\title{
DERECHOS HUMANOS EN COLOMBIA: UNA REVISIÓN DE LOS INFORMES DE LA OFICINA DEL ALTO COMISIONADO DE LAS NACIONES UNIDAS PARA LOS DERECHOS HUMANOS (2003-2015)
}

\author{
HUMAN RIGHTS IN COLOMBIA: \\ A REVIEW OF THE REPORTS OF THE UNITED NATIONS HIGH \\ COMMISSIONER FOR HUMAN RIGHTS (2003-2015)
}

José Alonso AndRade SAlaZAR*

\author{
Recibido: 20 de junio de 2019 - Aceptado: 15 de agosto de 2019 \\ Publicado: 30 de diciembre de 2019 \\ DOI: $10.24142 /$ raju.v14n29a2
}

\section{Resumen}

Este trabajo tiene como fin revisar los informes sobre derechos humanos en Colombia de la Oficina del Alto Comisionado de las Naciones Unidas para los Derechos Humanos, en busca de evidencia que de-

* Psicólogo, Universidad Salesiana de Quito. Ph.D. Pensamiento Complejo, Multiversidad Mundo Real Edgar Morin. Magíster en Investigación Integrativa, Multiversidad Mundo Real Edgar Morin. Docente investigador Universidad de San Buenaventura, Medellín, extensión Armenia. Google Scholar: https://scholar.google.es/citations?user=qtbkl48AAAAJ\&hl=es, CvLAC: http:// scienti.colciencias.gov.co:8081/cvlac/visualizador/generarCurriculoCv.do?cod_rh=0001338914, Orcid: https://orcid.org/0000-0001-7916-7409. Correo electrónico: jose.andrade@usbmed.edu.co. Agradezco fraternalmente a las estudiantes de décimo semestre de la Universidad de San Buenaventura, Medellín, extensión Ibagué, Diana Carolina Pinilla Rojas y Lizzy Dayhanna Cárdenas Gutiérrez, por su colaboración en esta investigación. 
muestre la interrelación anulativa de los actores sociales del conflicto armado en contra de la dignidad de las victimas. La violencia y todo acto de terrorismo emergente del conflicto armado aumentan la vulnerabilidad, el silenciamiento de la memoria, la impunidad y, en gran medida, promueve una lógica evasiva de responsabilidades y reparaciones que son necesarias para esclarecer los hechos victimizantes y otorgar voz a los afectados. El conflicto armado sume a las víctimas en una dinámica del terror que impacta todas sus áreas de desarrollo y limita su sentido de seguridad, confianza y credibilidad en el otro y en las instituciones sociales.

Palabras clave: Actos de lesa humanidad, conflicto armado, derechos humanos, derecho internacional humanitario, psicología, violencia.

\section{Abstract}

The purpose of this work is to review the reports made by the United Nations High commissioner for Human Right on human rights about Colombia, in search of for evidence that demonstrates the nullifying interrelations between social actors of the armed conflict against the dignity of the victims. Violence and any act of terrorism emerging from the armed conflict increase vulnerability, the silencing of memory, impunity and to a large extent, promotes an evasive logic of responsibilities and reparations that are necessary to clarify the victimizing facts and give voice to those affected. The armed conflict brings victims together in a dynamic of terror that impacts all their areas of development and limits their sense of security, trust and credibility in each other and in social institutions.

Keywords: Acts against humanity, armed conflict, human rights, international humanitarian law, psychology, violence. 
Derechos humanos en Colombia: una revisión de los informes de la Oficina del Alto

Comisionado de las Naciones Unidas para los Derechos Humanos (2003-2015)

\section{INTRODUCCIÓN}

La defensa y respeto de los Derechos humanos en Colombia, en el marco del conflicto armado y la violencia social, es crítica. De acuerdo con la Oficina Internacional de los Derechos Humanos Acción Colombia (OIDHACO, 2014), Colombia es el sexto país con desigualdad social marcada en el planeta (vivienda digna, trabajo, alimentación, agua potable, acceso a educación y salud, recreación, etc.), aspecto asociado al aumento de la pobreza y la miseria, la impunidad y la violencia, como también al despojo consecutivo de las comunidades de territorios ancestrales, con fines de apropiación de los recursos mineros y agrícolas. Como consecuencia, se estima que más de seis millones de hectáreas han sido arrebatadas a pueblos indígenas, afrodescendientes y campesinos a causa de la violencia sociopolítica (Quiñones, 2012). De suyo el conflicto violento ha devenido en una crisis humanitaria a gran escala, que desborda la capacidad asistencial-operativa del Estado y sus instituciones, para dar respuesta a la demanda reparatoria de las víctimas, especialmente porque los abusos de poder se construyen y reproducen sobre la base de masivas violaciones a los derechos fundamentales de las poblaciones (IECAH, 2013; CICR, 2012 y República de Colombia, 2013a). Evidencia de ello es que las masacres, desapariciones forzosas, desplazamientos, persecuciones, silenciamientos, asesinatos, ejecuciones extrajudiciales, además de la tortura, la sevicia y las violaciones sexuales, constituyen acciones frecuentes en el marco del conflicto (República de Colombia, 2010; MINISALUD, 2013; CICR, 2012 y OIDHACO, 2014), por lo que sus efectos amplían su impacto a los ámbitos de interacción familiar, comunitario y social.

Según la OIDHACO (2014) preocupa sobremanera que el estado de impunidad, en relación con los eventos de violaciones a los derechos humanos, se aproxime al 98\%, lo cual exhibe la persistencia de los actos de lesa humanidad, así como también la incapacidad del Estado para ofrecer garantías de seguridad respecto a la protección y legitimidad de los derechos humanos. Del mismo modo, la Oficina del Alto Comisionado de las Naciones Unidas para los Derechos Humanos en Colombia (HCHR), informó que los actos de lesa humanidad presentan un crecimiento importante y que muchas de las acciones para contrarrestarlos han devenido en reincidencias en el delito, ya que las autoridades colombianas calculan que entre el año 2003 y el 2006, de los 30.000 paramilitares desmovilizados una proporción importante re- 
gresó a la delincuencia, ingresando a grupos de narcos, crimen organizado y bandas criminales, que son actualmente acusados de asesinatos, secuestros, extorsiones, entre otros delitos; tópico al que debe sumarse la probable liberación de líderes paramilitares sin enjuiciamiento previo, tal como lo estipula la ley 975 de 2005, llamada Ley de Justicia y Paz, impulsada durante el gobierno de Álvaro Uribe Vélez ("La ONU raja a Colombia en Derechos Humanos", 2014). Otros aspectos asociados a la impunidad en el marco de los derechos humanos, según Todd Howland, representante del HCHR en Colombia, son el despojo consecutivo de tierras campesinas y la depredación de los recursos naturales. ${ }^{1}$ A ello debe sumarse el asesinato de activistas y familias, especialmente en zonas rurales, la persistencia del conflicto de los años cincuenta en territorios al parecer históricamente determinados como zonas de violencia, el incremento de la confrontación armada y la constante violación a los Derechos Humanos (DD. HH.) y al Derecho Internacional Humanitario (DIH) en varias regiones del país, aún con una elevada presencia de organismos de orden público y el cuestionamiento de los rubros entregados — según la Fiscalía - por los desmovilizados que ascienden a 6.300 millones, los cuales son muy bajos, de acuerdo con las afirmaciones de varios activistas de DD. HH.

Actualmente, el país cuenta con más de cinco millones de personas en situación de desplazamiento forzado (CODHES, 2013a) y de ellas 256.590 personas se desplazaron en el año 2012, lo que quiere decir que cerca de 65.748 familias fueron desterradas y optaron por desplazarse para proteger sus vidas, "como consecuencia de las vulneraciones sistemáticas a los derechos humanos de la población civil por parte de los grupos armados vinculados a los conflictos y por la insuficiencia de medidas oportunas, pertinentes y eficaces de protección por parte del Estado" (p. 12). Para la entidad, el aumento de la violencia estructural, la creciente vulnerabilidad de las comunidades y la dinámica del despojo consecutivo sobre estas poblaciones, pone en tela de juicio las declaraciones acerca de una recuperación de la legitimidad de los DD. HH. en Colombia, aspecto que invita a las organizaciones a persistir en la intervención en los ámbitos de prevención, atención y reparación a las víctimas (CODHES, 2013b). Según cifras del Programa Presidencial de Dere-

1 Según el programa de restitución de tierras de la Comisión Nacional de Reparación y Reconciliación, las tierras despojadas a las personas desplazadas se calculan aproximadamente en tres millones de hectáreas, al tiempo que las encuestas realizadas a esta población indican "de al menos 6,5 millones de hectáreas de tierras despojadas en diversas modalidades, sin contar las tierras de propiedad colectiva" (Naciones Unidas, 2011, p. 11). 
Derechos humanos en Colombia: una revisión de los informes de la Oficina del Alto

Comisionado de las Naciones Unidas para los Derechos Humanos (2003-2015)

chos Humanos y Derecho Internacional Humanitario (PPDH-DIH) (2013), a julio de 2012 es notable la comisión de 8.058 homicidios, 14 masacres (66 víctimas de masacres), 3 homicidios de dirigentes políticos y de 10 sindicalistas, 196 secuestros y 3.284 personas expulsadas (registradas en el Sistema de Información de Población Desplazada —SIPOD—); además de 1.815 casos de minas antipersonales (MAP) y municiones sin explotar (MUSE), tópicos que constituyen violaciones a los derechos a la vida y la integridad. Cabe mencionar que estos datos provienen de varias fuentes institucionales y en realidad no reflejan la verdadera dimensión del fenómeno de la violencia en Colombia, ya que deja de lado a las personas que no han denunciado, a los desaparecidos y aquellos que se encuentran en fosas comunes cuyas muertes no han sido declaradas ante la autoridad competente.

Grosso modo, la violación de los derechos humanos no es un evento nuevo, dado que incrementa su accionar en un contexto sociopolítico de crisis transpartidista (más allá del bipartidismo) y por ello no puede ser explicado específicamente a razón de la lucha política entre partidos; del mismo modo, en la actualidad el conflicto armado responde a una compleja trama de acontecimientos, que traen consigo el resurgimiento y la resignificación de intereses de dominación, cooptación del poder y mantenimiento de la violencia en quienes extienden su dominio y atentan contra los derechos del otro (Rodríguez, 2014). En este sentido, "la guerra transforma a la gente. Hay un daño inmenso y casi irreparable" (CODHES y UNICEF, 1998) que a menudo no es mostrado por los medios masivos de comunicación (mass media) o suele ser aplacado por noticias que transforman los contenidos para favorecer intereses económico-políticos. Según la Comisión Interamericana de Derechos Humanos (CIDH) (2012) Colombia no ha logrado abandonar totalmente la lista de países latinoamericanos donde se violan frecuentemente los DD. HH. de las personas víctimas de la guerra, entre Estado e insurgencia; sin embargo, dicho contexto no es propiedad exclusiva de Colombia, ya que países como Venezuela, Cuba y Honduras presentan graves problemas de violación a los DD. HH. ("Colombia, en 'lista negra' de DD. HH.", 2012), contexto que no ha mostrado cambio en Colombia en relación con los años anteriores. ${ }^{2}$

2 En el 2012, la Comisión Interamericana de Derechos Humanos (CIDH) decide sacar a Colombia del Capítulo IV, que contiene el análisis de la situación de derechos humanos en Estados Miembros de la OEA, que requieren una atención particular. Esta acción se convierte en un referente positivo, en la medida que indica una mejora en la defensa y restitución de los derechos en el país (República de Colombia, 2013b). 
Respecto a Colombia, la CIDH resalta las notables dificultades del Estado para consolidar la desmovilización y reinserción de los reductos de las fuerzas paramilitares que aún operan, situación que no ha tenido el impacto deseado - incluso cuando se encuentran protegidas bajo la Ley de Justicia y Paz- y que forman la base de las estructuras de las nuevas bandas criminales (BACRIM), las cuales consolidan nuevos grupos armados. A estos elementos se suman las bajas condenas para los asesinos, las ejecuciones extrajudiciales o mal llamados "falsos positivos", efectuados presuntamente por miembros de la Fuerza Pública, y como corolario de todo este fenómeno el grave problema del desplazamiento forzado a nivel interno. ${ }^{3}$ Pese a esto, para las entidades internacionales no todo es inapropiado, puesto que, como aspectos positivos, se valora la Ley de Víctimas y Restitución de Tierras de 2011 (ACCIÓN SOCIAL, 2011) y la intención de implementar "más medidas que fomenten la restitución efectiva de tierras dada la persistencia de la violencia" (CIDH, citado en "Colombia, en 'lista negra' de DD. HH.", 2012). ${ }^{4}$ El conflicto armado, sus prácticas y consecuencias catastróficas, tales como masacres, secuestros, silenciamientos, acosos, reclutamientos, vejaciones, asesinatos y el desplazamiento forzado, generaron en esta última década elevados niveles de violencia contra mujeres y niñas, añadiéndose a esto la creciente militarización de la vida cotidiana, el aumento de la agresión escolar (Castañeda, Del Moral y Suárez, 2017) y el incremento de abusos y agresiones en contra de múltiples personas.

\section{DESCRIPCIÓN DE EVENTOS Y VIOLACIONES A LOS DERECHOS HUMANOS EN EL PERIODO 2003-2013}

Para entender la situación de los derechos humanos en Colombia es preciso tomar en cuenta el escenario sociopolítico y la situación de orden público preponderante. Hacia el año 2003 el poder del Estado se encontraba en manos del presidente Álvaro Uribe Vélez, y durante esa época se inten-

3 Estos casos son reconocidos por el Derecho Internacional Humanitario (DIH) como "ejecuciones extrajudiciales”; así mismo, en el Derecho Penal colombiano se les juzga como "homicidios en persona protegida" ("Falsos positivos”, 2013).

4 El HCHR (2011) indica que "el 10 de junio, el presidente Santos firmó la 'Ley de Víctimas y de Restitución de Tierras', ante la presencia del Secretario General. Esta ley podría ser considerada como el instrumento más importante de los últimos años para facilitar la búsqueda de la paz y la reconciliación en Colombia, partiendo del reconocimiento, promoción, protección y respeto de los derechos de las víctimas" (p. 11). 
Derechos humanos en Colombia: una revisión de los informes de la Oficina del Alto Comisionado de las Naciones Unidas para los Derechos Humanos (2003-2015)

sificaron, especialmente, los combates contra los grupos armados ilegales. Así, "durante el periodo de gobierno de Álvaro Uribe Vélez (2006-2010), la ejecución de la 'política de seguridad democrática' no solo no detuvo el desplazamiento forzado, sino que registró más de 2.500 .000 desplazados" (CODHES, 2010, p. 2). También en este año se firma un acuerdo con las Autodefensas Unidas de Colombia (AUC), que permite la desmovilización de muchos insurgentes sin cumplir con lo esperado por las instituciones. $\mathrm{Si}$ se examina la evolución del conflicto armado en Colombia, es visible que la guerra va de la mano con problemas del endeudamiento, por efecto de la deuda externa con Norteamérica, lo cual crea también una dependencia de Colombia respecto a las políticas de este país; por ello, las instituciones pierden gran parte de su independencia al momento de tomar decisiones políticas importantes, lo que crea un desequilibrio en el manejo de los recursos que llevó a que el país sufriera de un déficit fiscal importante. Igualmente, en este año se adoptaron nuevas medidas políticas bajo el cuadro del "estado de conmoción interior", y del posterior estado de cosas inconstitucionales, lo que restringió los derechos y libertades fundamentales de las minorías políticas. Estas medidas fueron aplicadas, en su gran mayoría, en las llamadas zonas de "rehabilitación y consolidación". 5

A la par, el gobierno central, bajo su política de "seguridad democrática" (Rojas, 2007), incrementó las operaciones militares en contra de los grupos alzados en armas, en especial los que tenían como objetivo los grupos insurgentes, mismos que al verse presionados se replegaron en áreas rurales y recurrieron a actos que el gobierno denominó "terroristas", cuyo fin era eliminar la presión ejercida por el Estado en ciertas zonas donde los grupos armados insurgentes presentaron una fuerte incidencia bélica, a razón del tráfico de drogas y el comercio ilegal de estupefacientes. En medio de esto también el gobierno promovió un referendo constitucional, el 25 de octubre (Wiesner, 2004), que tuvo como finalidad realizar cambios políticos-económicos en la Constitución Política de Colombia, situación que no

5 Estas zonas referencian a siete regiones específicas, que cubren catorce departamentos y veintitrés puntos considerados clave por las Fuerzas Militares; áreas en las cuales la confrontación entre las FARC, el ELN, las autodefensas y otros grupos armados ha agudizado el conflicto, presentándose las más elevadas cifras de desplazamiento, ataques, masacres, asesinatos, combates y secuestros. Las zonas fueron las siguientes: antigua zona de distensión: municipios de Vista Hermosa, Mesetas, Uribe y Macarena, en el Meta, y San Vicente del Caguán, en el Caquetá. Meta, Guaviare y Guainía. Chocó y Antioquia. Región del Catatumbo (Norte de Santander). Valle, Cauca y Tolima. Putumayo, Huila y Caquetá y Región del Sumapaz (Cundinamarca). "Media Colombia con zonas de rehabilitación" (2002). 
se pudo concretar por diversas presiones de los grupos políticos y sociales (HCHR, 2003). Conjuntamente, se realizaron elecciones presidenciales que dieron como resultado la reelección del candidato Álvaro Uribe Vélez, situación que desató apatía en muchos defensores de derechos humanos al considerar las acciones del gobierno como represivas en extremo, como también la simpatía de muchas personas que vieron en la política de seguridad ciudadana una respuesta total, anulativa y beligerante al tema del conflicto armado (Gómez, 2011), mismo que fue tomando la forma de "intervención por invitación"; es decir, de una especie de internacionalización del conflicto colombiano como efecto de la participación de otros países en las acciones militares y en la búsqueda de auxilios para las víctimas (Tickner, 2007). En el año 2003, en el tema de derechos humanos surgieron grupos insurgentes que buscaban ejercer control sobre ciertas zonas álgidas del país; cabe anotar que el HCHR afirma que estos grupos se enfrentan a una fuerza pública que en medio de la guerra creciente ya no toma en cuenta la sociedad civil (no diferencia combatiente de sociedad civil), por lo que de manera frecuente son violados los derechos de las poblaciones que quedan en medio de la guerra.

Durante el año 2003, según señala el informe del Alto Comisionado de las Naciones Unidas para los Derechos Humanos sobre Colombia, se registraron denuncias de violaciones a derechos como la vida, la libertad, la integridad, la seguridad personal y colectiva, al debido proceso y las garantías judiciales, al igual que "a la independencia e imparcialidad de la justicia, respeto por la vida privada y libertades fundamentales como derechos políticos, circulación, residencia, expresión y opinión" (s. d.). Este documento referencia que, en especial, son los servidores públicos los que con mayor frecuencia realizan este tipo de acciones, ya sea de forma directa o por omisión; ejemplo de esto es el caso de los servidores públicos que toleran actividades de grupos paramilitares (no denuncian o cooperan), lo que le otorgó continuidad a la incursión armada directa, especialmente en zonas donde la presencia del Estado es poca o ninguna, y que tradicionalmente se han constituido en baluartes territoriales de los grupos armados. En el año 2003, la CDIH, con base en el artículo 41 de la Convención Americana sobre Derechos Humanos, manifestó su preocupación sobre la posible incompatibilidad del estatuto antiterrorista que entrega poderes de policía judicial a las fuerzas armadas (OMCT, 2003). ${ }^{6}$

6 El estatuto antiterrorista confiere poderes a las fuerzas armadas militares (FF. MM.) para realizar incursiones, escuchas telefónicas (“chuzadas”), arrestos y detenciones sin autorización judicial, 
En ese mismo año, información suministrada al CDIH indicó que el gobierno del presidente Álvaro Uribe Vélez pretendió acabar con el Programa de Protección de los Defensores de Derechos Humanos y Sindicalistas colombianos, el cual se había avalado en el año 1998, aspecto que orientó dichas acciones hacia el desconocimiento del mandamiento constitucional centrado en proteger la vida, además de la honra y bienes de los ciudadanos, especialmente de quienes por su condición política y social corren peligro de forma permanente, población entre la cual se encuentran dirigentes sindicales y defensores de derechos humanos (Омст, 2003). La iniciativa de eliminación del programa fue considerada una señal política negativa, respecto al tema de inequidad en la política de seguridad democrática de poblaciones especiales, tales como líderes indígenas y comunitarios, campesinos, los operadores de justicia, las defensoras de derechos humanos, a razón de su género, quienes están mayormente expuestas a amenazas o ataques (principalmente sexuales) a su integridad (CDIH, 2003). Para el HCHR es preocupante que en el conflicto armado exista continuidad en la violación de todo tipo de libertades individuales y colectivas, en pro de un combate anulativo en el que la respuesta armada del Estado no logra sino agudizar su destructividad. Hacia el año 2004 el HCHR reveló que la atención de los medios de comunicación estuvo concentrada en el proceso de reelección presidencial, la negociación con los grupos paramilitares y los múltiples intentos de lograr un acuerdo humanitario que pusiera fin al secuestro de militares y políticos por parte de las Fuerzas Armadas Revolucionarias de Colombia (FARC).

La entidad informó que un avance en el tema de derechos humanos fue el diálogo del gobierno con la OEA sobre la creación de una misión que apoye el proceso de paz, aunque para el gobierno el punto principal en su agenda seguiría siendo las negociaciones con las autodefensas unidas de Colombia (AUC) (Bayer, 2010). Durante el 2004, se puso en marcha la mayor operación militar de la historia moderna colombiana denominada "El plan patriota o Campaña militar J. M." (D’Arcier-Flores, 2005). ${ }^{7}$ De este programa existieron denuncias acerca de procedimientos violentos y metódicos

con base en acusaciones militares producto de las investigaciones y sospechas, más que sobre la base de pruebas acumuladas en investigaciones judiciales de tipo independiente e imparcial en el marco de las autoridades civiles (OMCT, 2003).

7 Se denominó "Plan patriota" a la ofensiva militar de las fuerzas armadas, el cual se ejecutó a lo largo del río Caguán, los Llanos del Yarí y la Amazonía; su objetivo contrainsurgente fue el de recuperar el territorio, considerado por años como la retaguardia profunda de las FARC ("Plan patriota", 2006). 
de allanamientos, interrogatorios y detenciones con pocos o ningún fundamento probatorio, todo ello con base en la información compartida por desmovilizados o reinsertados y en los archivos de inteligencia militar, aspecto que respondía, en gran medida, al estatuto antiterrorista del año 2003. Paralelamente, a pesar de la disminución de las estadísticas de desplazamiento forzado, la movilización interna de personas víctimas del conflicto continuó siendo uno de los principales resultados de la guerra. Según el informe del Alto Comisionado de las Naciones Unidas para los Derechos Humanos sobre Colombia, del año 2004, el Estado, en medio de la lucha, tomó varias medidas positivas en materia de protección y prevención de violaciones a los derechos fundamentales, pero estas acciones se vieron aminoradas por afirmaciones públicas de altas autoridades del gobierno, que de una u otra forma deslegitimaban la tarea de los organismos del Estado como representantes de la defensa de los derechos humanos.

Lo anterior parece generar una idea, a grandes rasgos, que debe ser comprendida mejor y en profundidad a la luz de las intenciones político-económicas del Estado, de que el gobierno colombiano ejerce operaciones encaminadas a la protección de los derechos humanos en un marco de guerra y conflicto social, pero son los grupos insurgentes los que se resisten a aceptar la responsabilidad sobre cualquier tipo de violación a la dignidad humana, en gran medida porque no asumen que no deben hacerlo mientras no se encuentren inmersos en un proceso de paz, aspecto que, de acuerdo con Armengol y Fisas (2004), deja en una desventaja táctica a los grupos obligados a respetarlos, aunque su contraparte no haga lo mismo. Según los informes del HCHR, para los organismos defensores de los derechos humanos, las FARC-EP, el ELN y las AUC persisten en sus violaciones al DIH y no ejecutan acciones para respetar el medio ambiente, los territorios, las familias, las comunidades y las múltiples especies. Dicho así, el problema de estas violaciones es que tienen como víctima a la población civil que se convierte, frecuentemente, en "escudo humano" en medio de la guerra (Andrade, 2010). Uno de los delitos más comunes, cometidos indiscriminadamente por cualquiera de estos tres grupos, es el terrorismo, el cual es ejercido de diversas formas por los actores armados del conflicto. Entre los crímenes se encuentra el homicidio de personas protegidas, escenario en el que las víctimas suelen ser periodistas, sindicalistas y defensores de derechos humanos asesinados por efecto de sus acciones o convicciones políticas; otros delitos son la toma de rehenes, el secuestro, la persecución y el silenciamiento. Cabe anotar que para la mayoría de actores que no respetan el DIH, la ejecución extrajudi- 
Derechos humanos en Colombia: una revisión de los informes de la Oficina del Alto Comisionado de las Naciones Unidas para los Derechos Humanos (2003-2015)

cial y la utilización de MAP son actividades que afectan especialmente a la población campesina, aspecto al que se suman el reclutamiento forzado de menores de edad, la violencia sexual, el hostigamiento a las familias y también los bloqueos de alimentos o medicinas. El año 2004 se caracterizó por presentar una continuidad en los actos de lesa humanidad y la persistencia de ejercicios ofensivos de contrataque, poco efectivos por parte del Estado, con el fin de defender los territorios y las víctimas.

En el periodo comprendido entre el año 2005 y 2007, como referente positivo, el HCHR informa que la defensa y consolidación de las acciones en pro de los derechos humanos tuvo una notable restructuración, puesto que el punto central de este contexto fue la normatividad y la siempre constante prerrogativa del conflicto armado. Sin embargo, se debe resaltar que en este año (26 de enero de 2005) la CIDH (2005) condenó al Estado colombiano, y lo hizo responsable de la violación de los siguientes artículos: 4, que defiende el derecho a la vida, 5, que defiende el derecho a la integridad personal, y del artículo 7 o del derecho a la libertad personal de la Convención Americana, en detrimento de las "probables" víctimas de la masacre ocurrida en Mapiripán. ${ }^{8}$ Hacia el año 2005 los grupos al margen de la ley fueron el centro de la opinión pública, al jugar un papel muy importante en los escenarios sociales y políticos del país, entre ellos la llamada "desmovilización" de los grupos insurgentes que, a modo de "pacto inconcluso", constituyó un proceso inoperante o de acción incompleta, aun cuando se trataba de un elemento trascendental para generar una aproximación al equilibrio en el orden público, que hasta el día de hoy no se ha cristalizado efectivamente. En el año 2005 el HCHR indica que dos de los aspectos más importantes del contexto colombiano, que resultan directamente relacionados al desenvolvimiento del conflicto armado en el marco de los derechos humanos, son: 1) el debate sobre el Tratado de Libre Comercio (TLC) y 2) la reforma que se le hizo a la constitución, en la cual se consiente la reelección del presidente de la República.

Al respecto, Novoa (2005), refiriéndose al TLC, afirma que "en la implementación de la ciencia de la escasez no hay decisiones técnicas, estas

8 "Entre el 15 y 20 de julio de 1997 [...] aproximadamente un centenar de miembros de las Autodefensas Unidas de Colombia [...] con la colaboración y aquiescencia de agentes del [...] Estado, privaron de la libertad, torturaron y asesinaron a por lo menos 49 civiles, tras lo cual destruyeron sus cuerpos y arrojaron los restos al río Guaviare, en el municipio de Mapiripán, departamento del Meta". Así mismo, señaló que "aproximadamente 49 personas" eran las presuntas víctimas, de las cuales identificó a diez personas y a algunos de sus familiares" (CIDH, 2005). 
son de carácter político y conllevan un hondo talante ético" (p. 1) del que casi siempre quedan excluidas las poblaciones económicamente minoritarias; así mismo, en el tema de la reelección las implicaciones pueden ser mayores en el caso de los DD. HH., al tratarse de los antecedentes de violaciones continuas a los derechos humanos generados en este periodo de gobierno y su posible reedición o continuidad en un nuevo mandato. De esta manera, para el año 2005 "la situación de los derechos humanos se caracterizó por una serie de violaciones graves, vinculadas a los derechos civiles y políticos y a los retos pendientes en cuanto a los derechos económicos, sociales y culturales" (HCHR, 2005, p. 12). Este tópico resulta bien conocido por las instituciones del Estado, y aunque la norma que condena las violaciones está claramente estipulada, en realidad no es cumplida totalmente puesto que existen acciones colectivas de escasa resonancia política en contra de dichas violaciones, además de resistencias a su acatamiento por parte de colectividades económicas con poder político e influencias poderosas. Entre los temas relevantes en derechos humanos, en el 2005, se encuentran los desafíos políticos respecto a la desmovilización y su marco jurídico, la situación de grupos que se consideran fundamentalmente vulnerables, las políticas públicas encaminadas a la reparación de las víctimas y, por último, la implementación de recomendaciones para el crecimiento de las acciones y propósitos institucionales, factores que giran en torno al conflicto armado interno y el proyecto de desmovilización de la insurgencia armada y que alejan del foco de atención otros dominios de violación de los derechos humanos.

Las secuelas violentas del año 2005 alimentan la inseguridad vital de las poblaciones y el desconcierto sobre la capacidad del Estado para proteger a los ciudadanos (HCHR, 2006); por ello, en un primer momento, es posible constatar que la guerra interna colombiana funciona también bajo el prisma regulador de acciones interinstitucionales que operan aunadamente en la indagación del cumplimiento de los derechos humanos y del derecho internacional humanitario. Es así como no solo se busca la asistencia posvulneración de los derechos, sino también la prevención y educación en derechos (PLANEDH, 2006); desde el punto de vista de la reparación, las acciones incluyen el castigo a las infracciones bajo la justificación inalienable de los derechos humanos. Para el HCHR se tuvo un avance en el 2006, en particular con base en la contraofensiva militar del gobierno, el cual buscó producir un conflicto controlado de acuerdo con su tiempo de ofensiva, elemento importante en materia de derechos humanos, puesto que la contradicción disyuntiva entre los bandos "buenos y malos" primaba en la sociedad colombiana 
y en todos los marcos de comunicación interinstitucional y poblacional, lo cual fue reciamente influenciado por los medios de comunicación. Dentro de este año se manejaron políticas públicas y se realizó un seguimiento especial de las recomendaciones de la OEA en materia de DD. HH. y del proceso de desmovilización y reintegración, así "el contexto de violencia y conflicto armado que vive Colombia siguió afectando el goce de los derechos humanos y libertades fundamentales y dificultando la actuación de las autoridades en materia de prevención y protección" (HCHR 2006, p. 23). Nótese, de manera especial, cómo se va transitando desde el concepto de "reinserción" al de "reintegración", aspecto que en gran medida tiende a humanizar la desvinculación de las personas militantes en los grupos subversivos.

Durante el 2007, el contexto nacional no cambió mucho, ya que "Colombia continúa seriamente afectada por el conflicto armado interno que se remonta a más de cuatro décadas. Es también cada vez más evidente que los grupos armados ilegales están involucrados de manera directa o indirecta en actividades de narcotráfico" (HCHR, 2007, p. 36), además de encontrarse asociados a redes locales e internacionales de crimen organizado y de corrupción (Aristizábal, 2018). En este recuadro de acciones la población civil sigue siendo la principal víctima del conflicto, pues muchas personas se ven involucradas en situaciones de lesa humanidad y violaciones al DIH (SICSAL, 2007); a esto se suman los escándalos de la "narcopolítica" y la parapolítica, neologismos con los que se denominaron las acciones de involucramiento-participación-cooptación del poder de líderes políticos del Estado con la mafia y con organizaciones paramilitares, y aunque cuando estas últimas hayan ingresado al proceso de desmovilización, las consecuencias de sus acciones tienen una permanencia importante en las víctimas y en la sociedad en general (SICSAL, 2007). ${ }^{9}$ A la relación compleja entre todos estos factores es dable adicionar la permanencia de dificultades inscritas en la base de la estructura política del país: impunidad, desigualdad política, clientelismo, cooptación del poder, infiltración del narcoparamilitarismo en las instancias del poder político, entre otros factores transversales que continúan perturbando el goce efectivo de los derechos humanos en Colombia (HCHR, 2007).

9 De acuerdo con el Servicio Internacional Cristiano de Solidaridad con los pueblos de América Latina (2007), Colombia es el país que tiene la cifra más alta de asesinatos de defensores de los derechos humanos. La Comisión Colombiana de Juristas (CCJ) reveló que 44 defensores fueron asesinados en el año 2007; 39 de ellos eran sindicalistas. 
En el 2008 Juan Manuel Santos es nombrado Ministro de Defensa, y como jefe de cartera es uno de los funcionarios más próximos al presidente Álvaro Uribe, esto lo ubica, estratégicamente, en una posición política de manejo e interjuego de poderes. En esta dinámica, se enmarcan la consolidación del movimiento político que los respalda, el monopolio de cargos públicos, además de los proyectos de gobernabilidad conjunta que resultarían, a futuro, problemáticos, disociativos y contradictorios. ${ }^{10}$ Es posible afirmar que la continuidad del mando político ya tenía en su indicio hereditario el germen heteronómico de una indisoluble tendencia al cacicazgo. En este año se realiza una encuesta de intención de voto de los colombianos y aparece el nombre de Juan Manuel Santos junto al de Germán Vargas Lleras; ambos se convierten en los más fuertes aspirantes a la presidencia de la República. Paralelamente, se dieron cuatro hechos que marcaron la historia sociopolítica del país y que, a modo de hélices impulsoras, abrieron vía a la candidatura de Santos: 1) la Operación Jaque, 2) la confirmación de la muerte de Manuel Marulanda, 3) la polémica muerte de Raúl Reyes y 4) el escándalo por los mal llamados "falsos positivos", cuyo nombre real es de "ejecuciones extrajudiciales".

Ergo, en Colombia las hélices impulsoras que movieron al gobierno hacia la búsqueda de una respuesta cada vez más armada y menos dialógica ante el conflicto fueron cuatro: 1) la continuidad del negocio de la guerra, en el que opera la lógica anulativa: "hay más desplazados para que haya guerra" y no el argumento de que "hay desplazados porque existe la guerra" (ambos contradictorios y anulativos), 2) el juicio constante de las organizaciones internacionales acerca de la violación a los derechos humanos y al DIH por parte de todos los actores armados del conflicto, 3) el aumento de la impunidad por ejercicio, veredicto y ley, y 4) el incremento de las víctimas de la población civil como resultado del aumento de incursiones militares, además del cansancio social y la necesidad de recuperar-valorar la memoria e implementar la reparación integral de las víctimas. De acuerdo con lo expuesto, la dinámica negociadora del gobierno de Uribe implicaba tres condiciones de posibilidad de respuesta de las organizaciones subversivas:

10 La idea de "gobernabilidad conjunta" hace alusión a una de las formas invisibilizadas de dictadura; es decir, de perduración/mantenimiento/reproducción del líder, lo cual indica la tendencia a heredar el poder del Estado a quien es más cercano, representa o es fiel a los ideales políticos. Sin embargo, lo que sucedió en Colombia atentó contra la parte reproductiva de dicha herencia, desatando entre el mandatario saliente y el entrante constantes divergencias que fueron desde la descalificación hasta la ridiculización de lo político. 
rendición, negociación y extinción. Como efecto inmediato aumentaron los desplazados y la vulneración de sus derechos, al igual que las intenciones de rendición de algunos frentes subversivos. Otro resultado fue el detenimiento de las negociaciones que estaban en marcha previa a la Operación Jaque. Se debe aclarar que no es necesaria, in situ, una lectura negativa de estas operaciones, ya que se trata de resaltar la forma como el estado democrático social y de derecho es en realidad un proyecto, un proceso en construcción que ha pasado por diversas facetas y en cuyos andamiajes de poder las poblaciones menos favorecidas y excluidas históricamente se encuentran cada vez más victimizadas en medio de la guerra.

La Operación Jaque, realizada el 2 de julio de 2008, aun con los efectos positivos que tuvo sobre los nacionalismos bélicos y la efectividad de las fuerzas armadas, fue también una especie de show time que ocupó las primeras páginas de los periódicos y aumentó los presupuestos implementados para combatir las fuerzas subversivas. Los medios de comunicación ambientaron el suceso y algunas cadenas de televisión realizaron novelas, series y cortometrajes donde se replicaba el rescate; y aunque estos eventos no han sido muy bien datados en investigaciones, resulta interesante y crítico observar que la dinámica de la guerra ha permeado los distintos medios masivos de comunicación, llegando al punto de darles sentido a través de la novelación de los excesos sobre la vida, identidad y libertad de las víctimas, naturalizando la muerte y comercializando la dignidad de los pueblos a través del espectáculo. A través de todas estas facetas se mostró al mundo que la excandidata presidencial, Ingrid Betancourt, tres norteamericanos y once policías y militares habían sido rescatados "sin hacer ni un solo tiro". En esta operación, a pesar de que no hubo heridos ni muertos, se violaron convenios y acuerdos internacionales, a razón del uso de insignias de la Cruz Roja, lo que efectivamente puso en peligro futuras operaciones de ayuda humanitaria.

La segunda gran operación militar fue realizada el primero de marzo de 2008, de manera conjunta entre el Ejército, la Policía y la Fuerza Aérea; su corolario fue la muerte de Raúl Reyes tras el bombardeo a un campamento en territorio ecuatoriano. Acerca de este evento, se puede afirmar que fue el golpe más fuerte a las organizaciones de las FARC, pues por primera vez se daba de baja un miembro del Secretariado. Este hecho desató una crisis diplomática con Ecuador, Venezuela y Nicaragua, porque el bombardeo fue efectuado por aviones colombianos que incursionaron en territorio limítrofe. De igual manera, para este año las FARC-EP prorrogaron el desconocimiento 
de su obligación de someterse al DIH, dado que siguieron perpetrando profundas transgresiones y anulaciones sistemáticas: masacres, silenciamientos, homicidios, secuestros, toma de rehenes, uso de minas antipersona, violencia sexual, reclutamiento de niños, niñas y adolescentes, además de otras acciones terroristas (HCHR, 2008). En este periodo fue preocupante el impacto de los desplazamientos forzados provocados por grupos armados ilegales surgidos del proceso de desmovilización de organizaciones paramilitares, especialmente en los departamentos de Antioquia, Chocó, Córdoba y Nariño, según datos suministrados por la Comisión de Seguimiento a la Política Pública sobre el Desplazamiento Forzado (CSPPDF, 2008).

Durante el año 2009, los escándalos tuvieron en su gran mayoría un tono político, en relación con el tráfico de influencias y los carteles de contrataciones, como también las conocidas "chuzadas" o interceptaciones a teléfonos de personalidades del país por parte del Departamento Administrativo de Seguridad (DAS). El segundo escándalo fue el manejo del programa Agro Ingreso Seguro, un proyecto del gobierno colombiano creado para entregar subsidios a agricultores de bajos recursos y que fue puesto en marcha por el Ministro de Agricultura Andrés Felipe Arias. En este programa se encontraron irregularidades de ejecución en la contratación sin los debidos estudios técnicos, además de que los beneficios económicos fueron otorgados a familias terratenientes, lo cual era contrario a lo estipulado en el proyecto que debía favorecer a los más necesitados. Un aspecto positivo fue que en este mismo año la Corte Constitucional determinó, por medio de sentencias jurídicas, que las personas con discapacidad son víctimas constantes de violaciones a sus derechos humanos, principalmente en el marco del conflicto armado, en sus derechos a la educación, trabajo y salud (HCHR, 2009), por lo que debían ser reparadas de forma integral. En cuanto al desplazamiento forzado, se evidenció un aumento en este año con un continuo subregistro de casos, y aunque el incremento se dio en menor medida que en años pasados, cada persona o familia desplazada, cada desaparecido o muerto por efecto del conflicto armado, es en realidad la evidencia de la inoperancia del Estado y de sus instituciones en la consecución de una paz duradera con equidad y seguridad integral.

En el 2009, en casi todo el territorio nacional, se verificaron desplazamientos forzados, principalmente en zonas de hostilidad entre actores armados (HCHR, 2009). Cabe precisar que la desmovilización de paramilitares amplió la entrada de personas desmovilizadas a nuevos escenarios sociales; sin embargo, muchos de ellos ejercieron actividades delincuenciales, como, 
Derechos humanos en Colombia: una revisión de los informes de la Oficina del Alto Comisionado de las Naciones Unidas para los Derechos Humanos (2003-2015)

por ejemplo, en Medellín, donde se produjo una especie de paramilitarización de la ciudad, lo que puso en evidencia un proceso ficticio de desmovilización (Pizarro, 2009, citado por Insuasty, Balbín, Bastidas, Carrión, Pineda y Mejía, 2010) en el que "el mando y la dirección siguieron en la ciudad, el control paramilitar ahora, ya no, únicamente bajo la lógica armada, sino acudiendo a la intimidación y el manejo del miedo" (Insuasty, Balbín, Bastidas, Carrión, Pineda y Mejía, 2010, p. 65). La Organización de las Naciones Unidas (ONU, 2010) indica que en Colombia la falta de atención integral a las víctimas y la poca prevención del desplazamiento han hecho que las cifras de víctimas se incrementen y eleven la violación a los derechos humanos en el país, aspecto también asociado a una "ley de justicia y paz" inoperante e inequitativa con bajas sentencias condenatorias. La ONU expresa que existe connivencia entre las fuerzas armadas y los paramilitares, y que dicha tolerancia aumenta la impunidad, las agresiones a defensores de derechos humanos además de la creación de nuevos grupos armados con tendencia al paramilitarismo ("ONU alerta por graves violaciones de derechos humanos en Colombia", 2010). ${ }^{11}$ El aumento del desplazamiento forzado (3,3 millones de personas) fue análogo a las ejecuciones extrajudiciales, desapariciones forzosas (2.901 cadáveres exhumados en el 2009), tortura, violaciones sexuales (183 violaciones sexuales remitidas por la Corte Constitucional a la Fiscalía General de la Nación) y el reclutamiento de niños y niñas en el conflicto armado ("ONU alerta por graves violaciones de derechos humanos en Colombia", 2010).

De acuerdo con el HCHR (2009a), en el año 2009, los indicadores de derechos humanos y DIH, para Colombia, evidencian que en el país hubo 114.602 personas desplazadas, además de " 15.817 homicidios, $2 \%$ (323) menos que los perpetrados en 2008, año en el cual acaecieron 16.140 muertes violentas, manteniendo la tendencia descendente que se viene presentando desde 2003, aunque no de manera tan pronunciada como en años ante-

11 El Comité de Derechos Humanos de la ONU indica que en el 2009, y parte del 2010, "la atención para la población desplazada sigue siendo inadecuada, y caracterizada por la asignación insuficiente de recursos y la falta de medidas integrales para brindar una atención diferenciada a las mujeres, los niños, los afrocolombianas y los indígenas (artículos 12, 24, 26 y 27), [...] expresa su desacuerdo con la utilización de niños en actos cívicos militares, como el programa 'soldado por un día', y que se realice interrogatorios de niños con el propósito de recoger inteligencia (artículos 2, 7, 8 y 24)" (ONU, 2010). Los departamentos más expulsores fueron Nariño, Antioquia, Tolima, Cauca, Caquetá y Putumayo, que tuvieron entre 5.000 y 17.000 personas desterradas. 
riores" (p. 1). ${ }^{12}$ Hubo un incremento de homicidios en San Andrés, Sucre, Antioquia, Atlántico, Córdoba, Bolívar, Tolima y Guaviare; Valle del Cauca exhibe la mayor tasa de homicidios a nivel nacional, especialmente por efecto de las disputas relacionadas con el narcotráfico. En este año hubo 28 homicidios de maestros sindicalizados y sindicalistas, y 74 sentencias por estos hechos (uno más que en el 2008), también 14 homicidios de autoridades locales, tres periodistas asesinados en situaciones poco claras, según el Comité para Proteger a Periodistas (CPJ, 2009), además de 106 homicidios a indígenas (60 de ellos de la comunidad awa). Se produjeron 29 masacres -8 menos que en 2008-, 11 de ellas en Antioquia y 8 en Nariño, que dejaron 147 víctimas; así mismo, "según información del Centro Nacional de Datos de Fondelibertad, en 2009 los secuestros presentaron una disminución del $51 \%$ con respecto a 2008, al pasar de 437 a 213" (ACNUR, 2009a, p. 31). Los secuestros se produjeron mayormente en Nariño y Bogotá (22 y 18 casos). Análogamente, otros hechos que afectaron el goce efectivo de los derechos humanos en al año 2009 fueron:

Graves irregularidades en las que se vio involucrado el Departamento Administrativo de Seguridad (DAS), la persistencia de tensiones entre el Gobierno y la Corte Suprema de Justicia, incluyendo el impase en la elección del Fiscal General de la Nación, las dificultades para lograr más liberaciones de secuestrados por las Fuerzas Armadas Revolucionarias de Colombia-Ejército del Pueblo (FARC-EP) [...], el continuo incumplimiento del derecho internacional humanitario por parte de los grupos guerrilleros y sus ataques contra la población civil, y la polarización política alimentada por la incertidumbre de un posible referendo que abriría la puerta a una segunda reelección del presidente Uribe (Naciones Unidas, 2010, pp. 5 y 7).

Para el año 2010, la Corte Constitucional hundió, de manera definitiva, el proyecto de ley que convocaba al referendo reeleccionista, que determinó que el expresidente Álvaro Uribe no podría volver a ser candidato presidencial y al consejo. Luego, Juan Manuel Santos ganó las elecciones

12 Para el ACNUR (2009a), "es importante destacar que durante dicho periodo se presentaron disminuciones superiores al $35 \%$ en la totalidad de los departamentos del país y en el Distrito Capital. En nueve departamentos se registraron descensos superiores al 70\%: Magdalena (94\%), Vichada (80\%), Risaralda y Valle del Cauca, con 75\% cada uno, Atlántico (74\%), Cesar y Vaupés con una merma de $73 \%$ respectivamente, Bolívar (72\%) y Sucre (71\%)" (p. 32). 
Derechos humanos en Colombia: una revisión de los informes de la Oficina del Alto Comisionado de las Naciones Unidas para los Derechos Humanos (2003-2015)

presidenciales, y en el mes de septiembre se produce la baja de Víctor Julio Suárez Rojas, alias Jorge Briceño Suarez o Mono Jojoy, quien era el jefe militar de las FARC y el segundo al mando de la guerrilla, en un bombardeo realizado por el Ejército, la Fuerza Aérea y la Policía en el departamento del Meta. El Mono Jojoy era considerado uno de los criminales más importantes de Colombia, en comparación con otros subversivos y jefes de carteles del narcotráfico ("Muere el Mono Jojoy, jefe militar de las FARC, en un bombardeo en Colombia", 2010). En octubre se reveló una conversación de los asesores del Grupo Nule, ${ }^{13}$ en que mencionaron irregularidades en la contratación de uno de los tramos del proyecto Transmilenio de Bogotá. Este escándalo, sumado a la ola invernal, retrasó aún más el cumplimiento de lo estipulado en el contrato. Otra violación grave fue la implicación de miembros de las fuerzas militares en los denominados "falsos positivos", concepto con el que se conoce a los actos de lesa humanidad ejecutados a finales del año 2008, que involucran directamente a participantes del Ejército en el asesinato de personas civiles inocentes, con la finalidad de hacerlos pasar por guerrilleros dados de baja en combate. Dichos crímenes buscaron presentar, ante las fuerzas armadas, indicadores de efectividad en la guerra, para aumentar el prestigio de las brigadas de combate.

La ejecución extrajudicial se constituyó en uno de los eventos que más daño hizo a la imagen del gobierno del presidente Uribe, las fuerzas armadas y el país, en la esfera nacional e internacional. Estos hechos, ocurridos a mediados de 2007, tienen como referente la petición de un delegado de las Naciones Unidas al ministro de defensa de aquel entonces, Juan Manuel Santos, y a Freddy Padilla de León, comandante de las Fuerzas Armadas, de encontrarse en el despacho de la ONU para transferirles información delicada, derivada de la denuncia de un soldado de la Brigada XIV con sede en Puerto Berrío. De acuerdo con la revista Semana ("La historia desconocida de los falsos positivos", 2011) el soldado denunció ante la ONU pertenecer a una pequeña unidad secreta cuyo fin era conseguir civiles humildes, para luego asesinarlos y hacerlos pasar por guerrilleros muertos en combate. Lo que

13 Se llamó Grupo Nule al grupo económico conformado por varios hijos de exministros y exgobernadores, de descendencia libanesa: Miguel, Manuel y Guido, convertidos en empresarios hace diecinueve años y creadores de MNV en Sucre, como fachada para llevar a cabo la mayoría de sus estrategias financieras. Comenzaron con pequeñas redes de gas y después ganaban contratos para pavimentar vías, construir calles y acueductos; paradójicamente, también hacían la interventoría de contratos estatales ique ellos mismos ejecutaban! o que licitaban para ganarlos por medio de documentos falsos ("Las seis preguntas claves del caso contra los Nule", 2011). 
motivó su denuncia fue el asesinato de su padre por su propia unidad, quienes ignoraban el parentesco y lo presentaron como "falso positivo". Santos y Padilla de León tomaron la decisión de realizar una investigación administrativa que desmiente lo dicho por el soldado, pero deja abierta la duda sobre la impunidad del Estado y la presencia de estas acciones terroristas. Seguidamente, Clara López, quien era la secretaria de gobierno de Bogotá, verificó que once jóvenes residentes en Soacha, Bosa y Ciudad Bolívar, que habían desaparecido, fueron encontrados en la ciudad de Ocaña, señalados como "muertos en combate" ("La historia desconocida de los falsos positivos", 2011). Cuando se compararon las fechas de las desapariciones con las fechas de los supuestos combates se comprobó que no habían pasado más de tres a ocho días entre ambos eventos, razón por la cual no era dable que en un periodo de tiempo tan breve dichos jóvenes fueran reclutados, entrenados, puestos a combatir y asesinados en una lucha contra el Ejército.

Para el HCHR (Naciones Unidas, 2010) los eventos en derechos humanos y del DIH que más impactaron el 2010 fueron: 1) la decisión del presidente Santos de comprometerse con la defensa y restitución de los derechos humanos, enfatizando en derechos económicos y sociales, además de anunciar la política de restitución de tierras y la ley 1408 del 9 de agosto de 2010 de homenaje a las víctimas de desaparición forzada, 2) el nuevo código penal militar que eliminó las violaciones de derechos humanos de la autoridad penal militar, 3) el esbozo de una ley de víctimas en la que se incluyó el proceso de restitución de tierras (CNRR, 2010), 4) el deseo de fortalecimiento de las relaciones entre el poder ejecutivo, la sociedad civil y el poder judicial, y de estos con los países vecinos, 5) el acercamiento de paz con las FARC-EP, 6) la muerte de algunos cabecillas militares de las FARC-EP, 7) el rescate y liberación de múltiples secuestrados, 8) la intensificación de hostilidades durante el segundo semestre del año y 9) la afectación de más de 2,2 millones de personas por efecto de las lluvias e inundaciones. En este año fue alarmante la tasa de homicidios, amenazas y acosos a quienes trabajaron por la defensa de los derechos de personas y comunidades desplazadas, principalmente periodistas y lideresas de grupos de mujeres, así como también los asesinatos por motivo del ejercicio del derecho a la restitución de tierras en las regiones del Cauca, Sucre y Urabá. Llaman la atención "los asesinatos de Rogelio Martínez, Alexander Quintero y Óscar Maussa, quienes trabajaban en casos de restitución, estaban amenazados y contaban con medidas de protección" (Naciones Unidas, 2010, p. 4). 
Para el año 2011, la violación a los derechos humanos sigue muy asociada al ejercicio de la violencia en el conflicto armado; así, "la violencia generada en el marco del conflicto armado interno y sus graves consecuencias humanitarias, como desplazamientos forzados, reclutamiento de niños, niñas y adolescentes, e incidentes por minas antipersonales, siguen afectando el pleno goce de los derechos humanos" (Naciones Unidas, 2011, p. 14), ya que la Corte Constitucional confirmó la persistencia del estado de cosas inconstitucionales, identificado en 2004 como causa principal de todas los ejercicios de impunidad respecto a las víctimas del desplazamiento forzado. Como dato curioso y paradójico, solo hasta este año el presidente Juan Manuel Santos admite públicamente que Colombia vive un conflicto armado interno y que sus consecuencias resultan innegables para la sociedad, las instituciones, el orden público y, especialmente, para las víctimas, consecuencias que en gran medida fueron escasamente reconocidas por gobiernos anteriores, cuya orientación bélica intensificó la guerra antes que los procesos de restitución y defensa de los derechos. Es importante mencionar que, de acuerdo con el HCHR, reconocer las violaciones a los derechos proporciona un diálogo honesto y provechoso con la comunidad internacional y las organizaciones de víctimas, además de promover la implementación de acciones legales de reparación y el uso de métodos, experiencias y posiciones análogas para describir la situación sociopolítica del país, atributo que favoreció la participación efectiva de la comunidad internacional en la defensa y restitución de los derechos humanos en Colombia (Naciones Unidas, 2011).

En este año el HCHR (Naciones Unidas, 2011) registra un gran número de ofensivas contra personas defensoras de derechos humanos, "lideresas y líderes comunitarios, sociales, afrocolombianos e indígenas, sindicalistas y periodistas. En el año 2011, fueron especialmente preocupantes los numerosos hostigamientos, las amenazas y las detenciones aparentemente sin una adecuada investigación" (p. 5), también se observa un avance en el esclarecimiento de las interceptaciones telefónicas, se aprueba la llamada Ley de Inteligencia, que pone límites y fines a la inteligencia policial y militar y la obliga a respetar los derechos humanos; pese a esto, la impunidad aumenta, ya que "la práctica de las ejecuciones extrajudiciales no se ha erradicado totalmente. La oficina en Colombia observó casos con características de esta grave violación en Arauca, Bogotá, Cauca y Cesar" (p. 8). El HCHR, en Colombia, observó con intranquilidad el continuo desarrollo de nuevos grupos armados ilegales ulteriores a la desmovilización de las grandes estructuras paramilitares, ya que "estos grupos que se organizan en torno al narcotráfico 
y otras actividades criminales, generalmente evitan enfrentarse con la fuerza pública y tienen un impacto abrumador en la vida de la población" (Naciones Unidas, 2011, p. 25). Otros temas importantes, asociados a los DD. HH. $\mathrm{y}$ al derecho internacional humanitario, fueron la necesidad de reformar la ley 975, que concede "ganancias" penitenciarias a personas desmovilizadas de los grupos subversivos, en canje a su contribución en procesos de verdad y reparación de víctimas, para lo cual el HCHR señala la necesidad de una reforma estructural en el marco de una justicia transicional, que redefina la ley de víctimas y la ley de restitución de tierras, además de crímenes de lesa humanidad como secuestros, masacres, desaparición forzada y ejecuciones extrajudiciales (Naciones Unidas, 2011). ${ }^{14}$

En el año 2012, el número y la frecuencia de episodios de violación a los derechos humanos en Colombia no cesó; de este modo, los conflictos entre los grupos armados y todos los actos de lesa humanidad derivados hacen que sea cada vez más difícil la regulación, defensa y cumplimiento de los derechos humanos, por ello su constante transgresión, por parte de los actores armados, limita la viabilidad de las diferentes reformas y acciones legales realizadas, por lo que son escasamente usadas como marco de referencia social en el conflicto; en algunas regiones, una parte importante de estas violaciones puede ser atribuida a personas y desmovilizados (Naciones Unidas, 2012) y su presencia mayoritaria en lugares de escaso dominio estatal. En este mismo año se dio continuidad a las agresiones y amenazas en contra de las personas defensoras de los derechos humanos y el DIH, los periodistas y la prensa, las organizaciones y aquellos vinculados al programa de restitución de tierras; Posada, Insuasty, Vega y Balbín (2009) indican que es necesario considerar otros problemas anexos a la restitución, tales como casos en los que no aplica el amparo, porque ya ha habido despojos, la falta de claridad respecto a las pérdidas de bienes como formas de victimización, una limitada formación de redes y organizaciones de víctimas que signifiquen sus intereses y la inconsistencia entre los datos de bienes abandonados o despojados recogidos.

14 Justicia transicional es el conjunto de medidas judiciales y políticas que diversos países han utilizado como ejercicio de reparación a las víctimas por las violaciones masivas de derechos humanos, especialmente cuando existen épocas de transición desde una situación de conflicto o de represión política hasta el desarrollo de políticas reparatorias concretas. Entre ellas figuran las acciones penales, las comisiones de la verdad, los programas de reparación y diversas reformas institucionales, lo cual genera en las víctimas el reconocimiento de sus derechos, a la vez que fomenta la confianza ciudadana y fortalece el estado social democrático y de derecho (ICTJ, 2014). 
Derechos humanos en Colombia: una revisión de los informes de la Oficina del Alto Comisionado de las Naciones Unidas para los Derechos Humanos (2003-2015)

En el 2012 se prioriza el proceso de paz, y el Centro de Memoria Histórica (CMH) y el ACNUR indican que "para transformar a Colombia se necesita un uso más eficaz del pasado" (CMH y ACNUR, 2012, p. 7); también se reconoce el papel de la defensoría del pueblo en la defensa y promoción de los derechos humanos y el trabajo de los personeros; se aumentan las medidas de protección de los defensores de los derechos humanos ante las amenazas frecuentes a su integridad. Sin embargo, como consecuencia de la intolerancia, los abusos de poder, la intensidad destructiva de la guerra y la violencia, a través de los años, sigue un curso devastador, de tal modo que:

La lista de violaciones es larga: asesinatos, desapariciones, torturas y otros malos tratos, uso de minas terrestres, desplazamiento forzado, violencia y explotación sexuales, estigmatización, amenazas e intimidación, reclutamiento y utilización de niños, restricciones a la libertad de movimiento y circulación de alimentos y medicinas, conculcación de los derechos a la educación, la salud, la libertad de reunión y de opinión, persecución del personal médico, limitaciones en el acceso humanitario y uso ilegal de la infraestructura civil (Naciones Unidas, 2012, p. 5).

Para el 2013 el HCHR enfatiza en los eventos positivos apoyados por el gobierno de Colombia, para impulsar y proteger los derechos humanos. Asî mismo, el Congreso de la República aceptó tres reformas constitucionales planteadas por el gobierno en el marco legal de la paz, cuyo objeto fue suministrar mecanismos de "justicia transicional", con el fin de proveer próximos procesos de paz. La reforma incluyó cambios importantes en el sistema de justicia penal militar, aceptadas a pesar de las fuertes críticas enunciadas a nivel nacional e internacional, primordialmente por la Oficina del Alto Comisionado de las Naciones Unidas para los Derechos Humanos. En este sentido, "la reforma al sector judicial fue rechazada por el presidente de Colombia por la indignación que suscitó entre la población y por los desajustes en relación con el objetivo original que se había fijado" (ACNUR, 2013, p. 7). Como efecto de rebote por esta irritación emergente, se acrecentaron las agresiones y amenazas en contra de los defensores de DD. HH., así como también contra aquellos que participaron del programa de restitución de tierras, situación ya presente desde el año 2012. En la mayoría de las regiones del país las amenazas se atribuyeron a los grupos armados ilegales emergentes posdesmovilización de organizaciones paramilitares, quienes al asegurar la 
explotación minera controlan el desarrollo económico de las zonas, lo cual aumentó la violencia en muchas regiones, además de incrementar los problemas bélicos, el control militar de grupos armados, las tomas miníferas y la violación a los derechos económicos, sociales y culturales. El conflicto manifiesto entre grupos armados, que se disputan los monopolios de territorios ricos en recursos naturales, versus el Estado, ha dejado una cantidad importante de víctimas, especialmente de las comunidades afrodescendientes, quienes se ven expuestas a constantes vejaciones y abusos por parte de los actores armados.

En este año se prolongaron las amenazas y agresiones contra los defensores de DD. HH., periodistas, población civil, etc., y para quienes participaron del programa de restitución de tierras (Naciones Unidas, 2013). En el mes de agosto de 2013 continuaron los diálogos entre el gobierno y las FARCEP en La Habana, Cuba, encuentro cuyo fin principal es la terminación del conflicto armado, la reparación integral de las víctimas y la construcción de una paz firme, estable y duradera en Colombia. En este espacio entraron en debate temas como el desarrollo agrario, la participación política de los grupos una vez desmovilizados, la terminación del conflicto armado y el cese al fuego bilateral, como también la relación de la subversión armada con las drogas ilícitas, la necesidad de reparación y los derechos de las víctimas del conflicto. Para las Naciones Unidas (2013) esto quiere decir que el proceso de paz busca transformar la dinámica del conflicto en su intensidad, el respeto de las diferencias y el goce efectivo de los derechos humanos, al tiempo que intenta provocar una metamorfosis significativa de la vida cotidiana de las víctimas y la población general (Naciones Unidas, 2013). Cabe indicar que los diálogos de paz se establecen aun cuando no se han terminado las acciones de guerra, por lo que muchos de los actos de maldad o de lesa humanidad permanecen como efecto de los combates entre partes aún en disputa, escenario en que muchas personas, familias y comunidades siguen siendo multivictimizadas por las acciones bélicas de los actores armados.

\section{Discusión}

El conflicto armado colombiano presenta variaciones y recursividades importantes, de acuerdo con los momentos en los cuales emergen los actos de violencia y represión social. La revisión de los informes alerta, en gran medida, sobre una relación directamente proporcional entre el aumento de la represión estatal y su arremetida ante los grupos armados, y el incre- 
Derechos humanos en Colombia: una revisión de los informes de la Oficina del Alto Comisionado de las Naciones Unidas para los Derechos Humanos (2003-2015)

mento de los actos de lesa humanidad en la población victimada por dichos eventos. Esta situación se produce de forma análoga en los subversivos, ya que ambos bandos exhiben estados de alerta ante cualquier provocación, escenario en el que una señal de peligro es considerada un ataque per se. Las variaciones en los actos de maldad y la "creatividad anulativa", en relación con la eliminación del otro al no reconocerlo como legítimo en la convivencia, guardan un vínculo con la tendencia, cada vez más marcada en el conflicto armado, de ejercer la violencia de forma indistinta a la categoría de etnia, género, vulnerabilidad, edad, combatiente, etc. Dichas acciones aumentan los actos de ilegitimidad vital, al tiempo que ponen en la palestra eventos de maldad y el abuso de poder o "sevicia" como argumentos, mecanismos e instrumentos centrales de dominación y convencimiento ideológico. Estos mecanismos obedecen, especialmente, a distractores planeados, "precipitadores del olvido" que al ser "implantados en el cerebro de los colombianos [impulsan] el olvido en la memoria [y evitan] que nos hagamos consientes y que reaccionemos de múltiples formas, que impidan que con indignación hagamos frente a la realidad" (Insuasty y Vallejo, 2012, p. 14).

La continuidad de la eliminación de personas y comunidades contrasta con la apatía de la gran mayoría de los grupos sociales, en cuanto acciones pasivas de no-oposición a la violencia y defensa de derechos de poblaciones vulnerables, de modo que la violencia se ha convertido, paulatinamente, en una especie de fetiche que solo cobra importancia para el común cuando su proximidad pone en entredicho la existencia; es decir, la violencia se ha constituido en "una potencia anónima que siembra la destrucción a su paso" (Pécaut, 1987, p. 490). Las consecuencias atroces de la violencia se propagan rápidamente a través de los medios de comunicación, mismos que presentan muestras claras del control político ejercido sobre la verdad y la memoria de las víctimas, y aunque no se constituye en el único medio puede ser considerado el más eficaz, por lo que se requiere de una transformación en la que se transite hacia una función "protectora-enunciativa" de la memoria, verdad y enunciación de la voz de las víctimas respecto a la realidad del conflicto; esto significa una función de recuperación de la memoria y de reconciliación social itinerante. Proporcional y paradójicamente, la violación de DD. HH. es parte fundamental de discursos amarillistas, que en muchos medios de comunicación visibilizan solo la parte anulativa de la dinámica de la guerra, sin percatarse de motivar en su ejercicio periodístico las acciones de paz; de suyo las víctimas sobreviven en la ausencia de garantías para la defensa, respeto, conservación, interiorización y reproductibilidad de los derechos 
humanos; es decir, en un territorio que sienten dotado de desprotección, abandono macro, meso y microeconómico, a lo cual se suma el descrédito en las fuentes y ejercicios de poder del gobierno que obstruye todo proceso de reconciliación. En este sentido, es claro considerar que:

Reconciliar implica encontrarse quienes han estado en conflicto, comprender el daño que se ha hecho, incluso el que se le ha hecho a cada persona, y buscar los medios para reparar tales daños, para conocer la verdad de lo sucedido y tener presente la memoria de la injusticia, de manera que no vuelva a repetirse jamás. En último término, se trata de reconstruir el tejido social roto y generar condiciones para una coexistencia y una convivencia pacíficas (Villa, 2007, p. 571).

Cabe anotar que la idea de unos derechos humanos que deben ser defendidos a toda costa instaura la trilogía básica de la interrelación entre "defensa-ataque-respuesta", relación que muestra claramente la instrumentalización de los derechos en el marco del conflicto armado bajo las premisas anulativas de: 1) defensa de la libertad y 2) ilegitimidad de la otredad, que en conjunto limitan la posibilidad dialógica de comprender los procesos de paz como garantes de una negociación sobre lo innegociable: la vida, paradoja en la que todo proceso de paz se estanca en sus propios objetivos, puesto que cuando no se logre negociar el derecho a la vida lo que se legitimaría, por contraste, es el derecho a la muerte; en consecuencia, es necesario cambiar la perspectiva y dirigirla hacia las acciones antagónicas-complementarias en torno a la protección, conservación y perdurabilidad de "lo vivo", es decir, a todas las especies, ecosistemas y sociedades, porque no se trata de qué derechos se deban reivindicar, sino de comprender que mientras la vida sea el privilegio del derecho, aquellos que los sienten vedados pueden considerar que su existencia es ilegítima; tal es el caso de las víctimas cuando la reparación no es integral-integrada o se limita a lo material. Para Maturana (1997), cuando en una sociedad se defiende la democracia se genera tiranía, porque la democracia solo puede ser vivida en el encuentro legítimo con el otro. Esta noción es una de las recursividades emergentes de la interacción humana, en cuyos fines se reproduce la organización social a partir del acuerdo, el diálogo y la negociación antropoética entre las partes; en este sentido, "la 'ética comunicativa' de Habermas, excelente desde el punto de vista de los procesos dialógicos sociales, ofrece aportes significativos para hacer expeditos los debates interdisciplinarios en que se mueve la bioética" (Cely, 2013, citado en Insuasty, 2013, p. 6). 
El enfrentamiento bélico produce dispositivos de guerra que operan en la dinámica excluyente del conflicto, a modo de motivaciones circulares anulativas de la diferencia, generando bandos en disputa interminable, de modo que "la Violencia está en relación con el hecho de que tanto lo social como lo político tienden a ser descifrados bajo el signo de la dialéctica 'amigo-enemigo" (Pécaut, 2003, p. 40) y no bajo la premisa que "la creación de un ambiente para la paz, conlleva al reconocimiento del otro y más si es adversario" (Insuasty y Vallejo, 2012, p. 17). En las relaciones anulativas existen recursividades y organizaciones inapropiadas, que en un escenario de guerra se orientan al manejo de la eliminación de personas y colectivos, porque su presencia es garante de sedición, revolución, atentados contra el orden estatal, violación a los derechos humanos, actos de lesa humanidad y abusos de poder, así como también de transformaciones sociales inherentes que operan de forma congruente con las vías por las cuales se puede modificar el ordenamiento social, por lo que reorganizan el sentido colectivo del discurso y del quehacer del sujeto en el escenario del conflicto armado. Como consecuencia de la autoeliminación mutua entre sectores armados que se disputan el poder, emergen de dichas interacciones dispositivos operacionales de maldad que coaccionan la libertad y la vida de las personas y colectivos, en distintos niveles o dominios de interacción social, llegando a retroactuarse de manera frecuente en las representaciones y construcciones histórico-socio-culturales, en las cuales se movilizan los sentidos sociopolíticos del conflicto. La evidencia encontrada en los informes del HCHR pone de relieve una complejidad inherente del conflicto, a razón del entrecruce reticular entre la multiplicidad de actores sociales, las posiciones ideológicas y las memorias y metáforas de la guerra, al tiempo que exhibe la capacidad de los dispositivos de guerra para perpetrarse en los sujetos, en sus discursos y sus relaciones.

Según Daniel Pécaut (2003), la violencia en Colombia deja entender que, en el pensamiento del común general, se trata de una fuerza anónima e incontrolable que se sustrae a las determinaciones sociales y es asumida como fetiche por las entidades e individuos más diversos. La violencia, como fenómeno, haría referencia al desplazamiento, el asesinato, la violación de los derechos humanos y el despojo consecutivo de tierras, gracias al auge de la economía de la droga, que atrae hacia regiones inmediatas no solo a personas y comunidades del sector rural, sino también a habitantes de los cascos urbanos, ya que "desde hace mucho tiempo las guerrillas no pretenden con sus acciones 'movilizar' o adoctrinar a las poblaciones, solo buscan 
afianzar su dominio sobre ellas e incluso asegurar el monopolio sobre las condiciones de acceso a los empleos locales" (Pécaut, 2003, p. 2). La masiva violación de los derechos fundamentales a la población colombiana presenta una linealidad destructiva que incluye masacres, vejaciones de todo tipo, asesinatos de defensores de derechos humanos, tortura, silenciamientos, secuestros, desapariciones forzosas y violaciones sexuales, dadas bajo la dinámica teleológica de acciones militares orientadas a la dominación, es decir, al constreñimiento de la capacidad transformadora — latente y manifiestade nuevos actores sociales que defiendan la liberación de las víctimas de aquellas premisas legales, imaginarios excluyentes y representaciones sociales negativas acerca de la vulnerabilidad, mismas que al interrelacionarse vulneran-limitan la capacidad-disposición para defender y ejercer sus derechos. En este sentido, es posible afirmar que más que un resultado de la guerra las personas desplazadas son asumidas como garantes de la misma, pues en ellas recae la reproducción de un conflicto que genera divisas, grandes donaciones en materia de dinero y de artefactos, proyectos de intervención bélica de otros países, capacitación externa en acciones destructivas, dominio sobre territorios explotables por multinacionales extranjeras, entre otros recursos; así la víctima se convierte en enunciado y predicado, es decir, en "presencia" (vida) y "ausencia" (muerte) en el marco del conflicto armado.

De acuerdo con los informes del HCHR, y otras entidades, a pesar de que el Estado colombiano tiene el deber de proteger a sus ciudadanos, está siendo muy cuestionado por el hecho de cometer graves violaciones a los DD. HH. y al DIH en el marco de un conflicto que, de acuerdo con su persistencia y pluralidad de actores amados, podría extenderse a un siglo de incidencia, por lo que personas, grupos políticos, facciones e instituciones del Estado son investigadas por posibles vínculos con narcotraficantes, guerrillas, paramilitares, bandas criminales y otros grupos ilegales de izquierda y de extrema derecha. Cabe precisar que, de la relación entre los actores políticos y la subversión armada surgen acciones de beligerancia e impunidad que han asolado al país por más de siete décadas. Para el GMH (2010), tanto la variedad como el alcance "de las modalidades de violencia en el conflicto colombiano [...] hizo evidente la convergencia entre el narcotráfico y los grupos paramilitares, [y] mostró tanto las alianzas del crimen con miembros de la Fuerza Pública, como la grave y persistente impunidad" (p. 26). Así mismo, las guerrillas están igualmente culpadas de cometer infracciones graves al DIH, tales como toma de rehenes, asesinatos, tortura, violencia de género, abuso de mujeres convirtiéndolas en armas de guerra, masacres, uso 
de minas y tanques de gas y reclutamiento forzado de niños, niñas y adolescentes (Andrade, 2010). En este enfoque es importante considerar que la efectividad anulativa de los grupos subversivos se basa en que operan a través de redes de relaciones de poder e intimidación, "que interfieren con otras redes de poder (narcotraficantes, militares, empresarios), que poseen igualmente una cierta capacidad de control sobre los recursos y las poblaciones" (Pécaut, 2003, p. 24), lo cual es evidencia de que en la actualidad Colombia se encuentra en una situación del conflicto civil generalizado, situándose a la cabeza de los estados violadores de los DD. HH. y ocupando el segundo lugar en cuanto al número de desplazados en el mundo. ${ }^{15}$

La violencia sociopolítica rompe la confianza al interior de los grupos poblacionales, porque en el imaginario social de las víctimas prima la inseguridad vital como percepción unívoca del abandono e ineficiencia del Estado en su función reguladora y protectora, condición a la que se añade el estado actual de conmoción violenta del país, la impunidad y apatía política y el aumento de los actos de lesa humanidad (Andrade, 2012); en este sentido, así como las comunidades tienen registro de la guerra, estas también pueden señalar las acciones necesarias acerca de la paz, por ello "se trata entonces de un proceso de decodificación de lo que se cree significa la paz" (Insuasty y Vallejo, 2012, p. 15), opción que puede centrar el conflicto en el marco de posibles soluciones más que en pro de la reproducción de las condiciones y mecanismos de anulación de la diferencia. Cabe señalar que la "ley del silencio" es soberana en zonas de violencia y no solamente se edifica como reflejo del terror, sino también como efecto de la desconfianza generalizada "de los unos con los otros", por lo que los desplazamientos se efectúan a través de este terror y bajo dicha desconfianza (Pécaut, 2001). Resulta complejo hablar de forma global de los "desplazados", ya que los desplazamientos aparecen en condiciones muy diferentes y con causas y consecuencias también distintas. En Colombia se presentan desplazamientos "organizados", donde los habitantes se encaminan hacia una zona próxima, en un principio para escapar del terror y la angustia vital experimentada, lo que ocasiona notables violaciones a sus derechos humanos. Según Ignacio Martín-Baró (2000), en los conflictos armados existen claras diferencias entre bandos que

15 De acuerdo con el informe del Consejo Noruego para los Refugiados, Colombia se constituye en el segundo país del mundo con más personas desplazadas, puesto que en el país existen 5,7 millones de víctimas, cifra que fue superada solo por Siria ("Colombia es el segundo país del mundo con más desplazados, según informe”, 2014). 
delimitan roles y motivaciones bélicas con las cuales se justifican fines y medios para la guerra, de tal modo que "el [rol] del enemigo constituye el estereotipo por excelencia que sirve para encarnar la causa que de otro modo resultaría ética y políticamente inaceptable" (p. 42), lo cual instituye dos tipos de terrorismo: terrorismo de estado y terrorismo subversivo.

En palabras de Daniel Pécaut (2001), la mayoría de desplazamientos son individuales y responden a amenazas, asesinatos, silenciamientos, persecuciones y toda actividad anulativa en el conflicto; sin embargo, también existen desplazamientos masivos generadores de "pueblos fantasma", por efecto de la arremetida bélica de las diversas fuerzas en disputa. Como consecuencia, toda acción bélica afecta los sentidos de pertenencia, arraigo y trascendencia en personas y comunidades, como también la preservación de la memoria histórica de los pueblos y el sentido antroposocial que las poblaciones en situación de desplazamiento forzado otorgan a su condición existencial. En gran medida, el conflicto armado niega y obstruye en las víctimas su condición de sujeto, tomándolo a partir de la postura de Edgar Morin (1983), es decir, como todo ser que por construcción y funcionamiento produce, trasmite y organiza información colocándose a sí mismo como punto de referencia y preferencia, ya que "es la ocupación exclusiva de este puesto egocéntrico lo que funda y define el término sujeto" (p. 196). En la guerra toda violencia se encuentra programada para negar esta condición y exaltar la ilegitimidad de la diferencia; por este motivo, en un escenario demoledor la creatividad-destructiva emerge de la tensión entre legitimidad-ilegitimidad, espacio donde cada parte intenta hacer valer derechos que cree sostienen legítimamente cualquier acción de abuso o destrucción. Para Morin (1984), la violencia elimina gradualmente la autorreproducción de los sistemas, de manera que puede permanecer oculta bajo diversas formas de sujeción y dominación, llegando a aniquilar ecosistemas a través de armas químicas, decisiones políticas, agentes biológicos y armas de guerra cada vez más tecnológicas y letales. En este punto, la defensa de los derechos humanos, al utilizar la guerra como referente de protección de la democracia, soberanía y legitimidad de los pueblos, "es una contradicción no admisible", cuando se habla de paz o de conciliación, y aunque pueda resultar útil en términos de reorganización del poder, generará igualmente devastación, ilegitimidad, discriminación, pobreza, terrorismo, aniquilación de ecosistemas y especies, cultura de la guerra y del terror, además de la persistencia de huellas de dolor imborrables que se anidan real, simbólica e imaginariamente al cuerpo, la memoria, las representaciones e imaginarios de las víctimas. 
Es preciso señalar que quizá del desconocimiento general de algunas de estas consecuencias devienen intervenciones que redundan en asistencialismos, en los cuales se trabaja solo la parte emergente del trauma de guerra, motivo por el cual sus medidas resultan paliativas dado que cambian parcialmente la continuidad de la experiencia traumática de la guerra, aunque por falta de prolongación de las acciones restitutivas pueden generar la idea de asistencialismo, incompletud e incoherencia en la reparación, es decir, la idea de que "algo faltó" o que "nunca será suficiente", lo cual puede complicar el sentir psíquico, familiar, comunitario y social con el que las víctimas han transformado la noción de sujeto, colectividad, familia, grupo, comunidad, sociedad o estado a causa de la guerra. De suyo, muchas intervenciones con las víctimas del conflicto armado se enfocan en talleres, convivencias, dinámicas grupales, modelos de intervención clínico-social y consejerías; sin embargo, omiten el hecho que la reparación debe observar primero lo inefable (Andrade, 2012), es decir, aquello que resulta irreparable, pero que puede ser resignificado en tanto se recupere la memoria individual y colectiva y se reivindiquen hechos, actores, situaciones, procesos, emergencias, causas y consecuencias, con un enfoque de justicia equitativa-transicional transparente y participativa, con la que se recupere no solo la dignidad a las víctimas, sino también que permita la equidad en el acceso y beneficio de la justicia. Al respecto, Villa (2012) opina que:

Más allá de las actividades concretas, de los talleres y de las intervenciones grupales. Más allá de una acción sobre malestares y síntomas subjetivos, más allá de la terapia, la acción psicosocial se comprende como una mirada, una perspectiva y, al mismo tiempo, una forma de enfocar la realidad que posibilita escenarios de actuación que comprenden los fenómenos humanos desde una visión integral y que por lo tanto plantean alternativas, soluciones y procesos incluyentes que se despliegan en el tiempo y que producen nuevas subjetividades en marcos de mayor justicia, equidad, desarrollo a escala humana, sana convivencia y paz (p. 362).

\section{CONCLUSIONES Y RECOMENDACIONES}

En el año 2003, especialmente, se incrementaron los combates contra los grupos armados ilegales, lo que aumentó la vulneración de los derechos humanos de las personas que habitan los escenarios de confrontación armada, 
de tal modo que en este año y en los venideros se continuaron cometiendo actos de lesa humanidad, tales como asesinatos, torturas, masacres, secuestros, vejaciones y otros crímenes que colocaron en alerta a la comunidad internacional —incluso más que a la comunidad nacional—; en consecuencia, estas organizaciones internacionales tomaron medidas de intervención, paradójicamente, antes que el mismo gobierno, quien parece estar más dirigido a la confrontación armada que al establecimiento de un proceso equitativo de reparación y justicia que incluya víctimas, victimarios, otros actores sociales y diferentes organizaciones con el fin de dialogar acerca de posibles vías recursivas que permitan resignificar, más que el concepto de paz, la experiencia y necesidad de verdad, justicia y reparación de las personas y colectivos que continúan siendo vulnerados en todos los escenarios que la guerra legitima. Esta condición ha caracterizado, penosamente, la dinámica destructiva de los años estudiados en esta investigación, lo cual ubica, en gran medida, al Estado colombiano en un territorio polivalente de impunidad, estado de cosas inconstitucionales y baja legitimidad de los derechos humanos.

Como resultado directo, en dichos territorios de intermediación política, las organizaciones subversivas y sus cabecillas, los líderes políticos vinculados a grupos de extrema derecha, narcotráfico u otros grupos bélicos de izquierda, han ejercido el poder de la intimidación, vejaciones y anulaciones selectivas contra líderes comunitarios, defensores de los derechos humanos, profesores sindicalizados, sindicatos, voceros barriales, líderes y otros grupos opositores. La impunidad ha llegado a tal límite que, a través de la ley de perdón y olvido, se ha producido la transición desde el ejercicio justo de la ley hasta la obtención de notables beneficios por "cooperación" con el Estado, actividad con la cual muchos crímenes aún quedan exentos. En todos los periodos y eventos de vulneración de los derechos humanos la dinámica destructiva y desplazante de la guerra ha evidenciado que el aumento de las operaciones militares incrementa la presencia, fortalecimiento, expansión y actividad de los grupos alzados en armas, y especialmente de grupos insurgentes que conforman células "citadinas-barriales" o agrupaciones subversivas. Estos colectivos pueden ser el producto de disidencias de otros grupos armados de izquierda y ultraderecha, que se instalan en barrios vulnerables donde una parte importante de la niñez y la juventud sobrevive con lo básico, por lo que se adhieren a estos como forma de acceso rápido al poder, por la búsqueda de estados de legitimidad en la coacción grupal, o como acción de resistencia ante la dominación política o de otros grupos empoderados territorialmente a causa del abandono estatal. 
Asimismo, en muchos casos la participación enunciada se debe a la pobreza y la falta de proyectos de vida sólidos y reales que se estructuren con base en las nociones de educación, participación, equidad social y corresponsabilidad del Estado y las instituciones para con las víctimas, reales y potenciales, de la dinámica expansionista que el conflicto armado presenta. Las denuncias de violaciones del derecho a la vida, integridad a la libertad, seguridad personal, al debido proceso y garantías judiciales no han desaparecido, y aunque el número de eventos muestra una baja considerable, se constituyen en uno de los indicadores del estado de crisis humanitaria que vive el país. Por esto, es necesario abrir las aldabas del olvido, que sellan con impunidad los territorios de legitimidad de la memoria colectiva, a fin de asegurar que todo proceso de restitución de derechos cuente con el registro y la afirmación de los hechos de crueldad que la historia de Colombia no puede suprimir por decreto o perdonar por ley. Para que todo proceso de verdad, justicia y reparación sea equitativo, se requiere comprender que la cultura de la paz es al mismo tiempo una cultura del conflicto, y que en ambos lugares todas las personas tienen una responsabilidad bioética con las víctimas, la humanidad y los ecosistemas.

En este tópico, más que defender los derechos para salvaguardar la democracia, se requiere con urgencia vivir los derechos y disfrutarlos bajo la lógica de las costumbres y la convivencia; es decir, en función del imperativo categórico kantiano, a través del cual todas las acciones de solidaridad, cooperación, empatía, conflicto constructivo, hospitalidad, recuperación de la memoria y conservación de la cultura e identidad de los pueblos, son en sí mismas acciones buenas de forma incondicional para los sujetos, comunidades, sociedades y el mundo, para lo cual es preciso modificar la forma como se piensa, distribuye, coopta y regula la relación entre poder-saber-transformación antropo-política. Dicho de otro modo, las propuestas de cambio político y las leyes que buscan generar equidad en la redistribución de la justicia no pueden estancarse en imperativos hipotéticos que impulsen, a través de dichas leyes, acciones solo dables o ejecutables en determinadas situaciones o circunstancias, como por ejemplo el acceso a beneficios especiales por información, la participación en escenarios de decisión política de criminales claramente reconocidos por sus actos de barbarie, y las dádivas por cooperación con la justicia cuando la atrocidad de los crímenes aún resuena y golpea la existencia de las víctimas, entre otros ejemplos que con claridad retratan la violencia y la sevicia con que se ha aniquilado a personas, familias y comunidades en el marco del conflicto armado colombiano. 
Es necesario implementar regulaciones antropoéticas a la política de estado, a fin de hacer de los territorios de transformación social, y de decisión del gobierno, espacios dialógicos de construcción de sujetos transformadores de la realidad violenta del país, para lo cual se demanda evaluar los procesos implementados para conseguir la paz, aprender y corregir los errores y aceptar que todo antagonismo es complementario, y que de la tensión entre puntos de vista divergentes es posible generar propuestas emergentes, con las cuales se reorganicen las interacciones entre personas, instituciones y colectivos, lo que abre paso a un diálogo que acoge la diferencia y acopla la incertidumbre, en un marco de legitimidad y, por ende, de respeto. La Oficina del Alto Comisionado indica que el logro de la paz se constituye en un imperativo para toda la sociedad colombiana, que requiere, a su vez, de la participación conjunta de todas las personas, grupos e instituciones del país. De allí la necesidad de asumir responsabilidades de sostén, acogimiento, verdad, justicia, reparación integral-integrada y garantías de no repetición de hechos victimizantes para las víctimas, al tiempo que una justicia transicional que permita la aplicación del derecho a los victimarios con miras hacia la restauración y la reconciliación social. Siguiendo a Humberto Maturana (1997), el amor es el respeto del otro como un legítimo otro en la convivencia, así la legitimidad se hace parte del acontecimiento y, por ende, todo encuentro se constituye en vivencia, más que una ley o registro con el que se seleccione o arbitre las inconsistencias de los procesos de restitución de derechos. Ergo, los derechos humanos no dejarán de estar en vigencia, no se podrán defender porque solo es posible vivirlos en la legitimidad del encuentro que reúne lo antagónico y lo torna complementario, unos derechos que se pueden enseñar de forma natural a través de la educación afectiva-conscientizante (Freire, 1970) con una educación que amplíe las barreras del pensamiento e invite a reformarlo, que lo torne relacional y multidimensional (Morin, 1990), cada vez más humanitario y responsable. 
Derechos humanos en Colombia: una revisión de los informes de la Oficina del Alto

Comisionado de las Naciones Unidas para los Derechos Humanos (2003-2015)

\section{REFERENCIAS}

Agencia Presidencial para la Acción Social y la Cooperación Internacional - ACCIÓN SOCIAL (2011). Ley de víctimas y restitución de tierras. http://www.centrodememoriahistorica.gov.co/micrositios/caminosParaLaMemoria/descargables/ley1448.pdf

Andrade, J. A. (2010). Mujeres, niños y niñas, víctimas mayoritarias del desplazamiento forzado. Revista Orbis Venezuela, 6(16), 28-53. http:// www.redalyc.org/articulo.oa? id $=70916426003$

Andrade, J. A. (2012). Aspectos irreparables de la pérdida. Aproximación psicoanalítica. Revista Kavilando, 4(1), 36-40. https://dialnet.unirioja. es/servlet/articulo?codigo $=4673635$

Aristizábal, A. (2018). Del individuo a la red: percepción de un Grupo Armado Organizado (GAO) colombiano desde la teoría de redes. Revista Criminalidad, 60(1), 111-131.

Armengol, V. F. y Fisas, V. (2004). Procesos de paz y negociación en conflictos armados. Paidós.

Bayer, A. K. (2010). El papel de la comunidad internacional en la construcción de la paz de Colombia: Europa, los vecinos de Colombia y las organizaciones internacionales. Instituto Universitario de Relaciones Internacionales y de Desarrollo.

Castañeda, A., Del Moral, G. y Suárez, C. (2017). Variables psicológicas comunes en la violencia escolar entre iguales y la violencia filio-parental: un estudio cualitativo. Revista Criminalidad, 59(3), 141-152.

Centro Internacional para la Justicia Transicional (ICTJ) (2014). ¿Qué es la justicia transicional? http://ictj.org/es/que-es-la-justicia-transicional

Colombia, en "lista negra" de DD.HH. (2012). El Espectador. http:// www.elespectador.com/noticias/politica/colombia-lista-negra-de-ddhh-articulo-337193

Colombia es el segundo país del mundo con más desplazados, según informe (2014). Noticias Caracol. http://www.noticiascaracol.com/nacion/ colombia-es-el-segundo-pais-del-mundo-con-mas-desplazados-segun-informe

Comisión Colombiana de Juristas (CCJ) (2007). Principios internacionales sobre impunidad y reparaciones. http://www.coljuristas.org/documentos/libros_e_informes/principios_sobre_impunidad_y_reparaciones.pdf

Comisión de Seguimiento a la Política Pública sobre el Desplazamiento Forzado (CSPPDF) (2008). Sexto informe a la Corte Constitucional, 
Proceso Nacional de Verificación. Junio de 2008. http://coeuropa.org.co/files/file/Resumenes_noticias/1\%20a\%2028\%20de\%20febrero.pdf

Comisión Interamericana de Derechos Humanos (CDIH) (2003). Informe sobre la situación de las defensoras y defensores de los derechos humanos en las Américas. http://www.cidh.org/countryrep/defensores/defensorescap6-8.htm

Comisión Nacional de Reparación y Reconciliación (CNRR) (2010). La reintegración: logros en medio de rearmes y dificultades no resueltas. II informe de la comisión nacional de reparación y reconciliación. http://viva. org.co/cajavirtual/svc0239/articulo028_239.pdf

Comité Internacional de la Cruz Roja (CICR) (2012). Situación humanitaria en Colombia. http://www.icrc.org/spa/assets/files/2013/colombia-report-2012.pdf

Comité para Proteger a Periodistas (CPJ) (2009). Ataques a la prensa en 2009. Versión en Español, Programa de las Américas. https://cpj.org/ es/2011/02/ataques-a-la-prensa-en-2019-analisis-de-americas.php

Consultoría para el Desplazamiento Forzado y los Derechos Humanos (CODHES) -UNICEF Colombia (1998). http://www.acnur.org/t3/filead$\mathrm{min} /$ Documentos/Publicaciones/2007/5161.pdf?view=1

Consultoría para los Derechos Humanos y el Desplazamiento (CODHES) (2010). Conferencia Regional Humanitaria sobre la protección de personas desplazadas y refugiadas: seguimiento a la Declaración y al Plan de Acción de México. https://issuu.com/codhes/docs/memorias_conferencia_ regional_human

Consultoría para los Derechos Humanos y el Desplazamiento (CODHES) (2013a). Documentos CODHES n ${ }^{\circ} 26$. La crisis humanitaria en Colombia persiste. El pacífico en disputa. Informe de desplazamiento forzado en 2012. http://www.lwfcolombia.org.co/sites/default/files/image/310513\%20 Informe\%20\%20desplazamiento\%202012.pdf

Consultoría para los Derechos Humanos y el Desplazamiento (CODHES) (2013b). Informe de CODHES sobre desplazamiento 2012. "La crisis humanitaria en Colombia persiste. El pacífico en disputa". http://www.lwfcolombia.org.co/node/146

Corte Interamericana de Derechos Humanos (CIDH) (2005). Caso de la "masacre de Mapiripán" vs. Colombia. Sentencia de 15 septiembre de 2005. http://www.corteidh.or.cr/docs/casos/articulos/seriec_134_esp.pdf

D'Arcier-Flores, H. (2005). Del Plan "Colombia" al Plan "Patriota": impacto del conflicto armado colombiano en el Ecuador, análisis de una 
Derechos humanos en Colombia: una revisión de los informes de la Oficina del Alto Comisionado de las Naciones Unidas para los Derechos Humanos (2003-2015)

estrategia de seguridad subregional. Revista Complutense de Historia de América, 31, 215-230.

Falsos positivos (2013). El Espectador. www.elespectador.com/tags/ falsos-positivos

Freire, P. (1970). La pedagogía del oprimido. Siglo XXI.

Gómez, J. C. (2011). Monasterio: de fallida operación militar a paradigma exitoso de la comunicación gubernamental en Colombia. Mesa N. ${ }^{\circ}$ 19 Resolución de crisis y conflictos políticos a través de la comunicación. Metodologías y experiencias, I Congreso Internacional en Comunicación Política y Estrategias de campaña. http://www.alice-comunicacionpolitica. com/files/ponencias/195-F500006a61951342178982-ponencia-1.pdf

Grupo de Memoria Histórica (GMH) (2010). ¡Basta ya! Colombia: memorias de guerra y dignidad. http://www.centrodememoriahistorica.gov. co/micrositios/informeGeneral/

Instituto de Estudios sobre Conflictos y Acción Humanitaria (IECAH) (2013). Colombia: entre la crisis humanitaria y la esperanza de la paz. http:// www.iecah.org/web/images/stories/publicaciones/informes/descargas/Informe8_2013.pdf

Insuasty, A. (2013). La nueva era "Bio": consideraciones políticas, éticas y filosóficas. Una reflexión para el porvenir. Editorial Kavilando.

Insuasty, A., Balbín, J. W., Bastidas, W., Carrión, J., Pineda, J. E. y Mejía, W. (2010). Las víctimas en contextos de violencia e impunidad. Caso Medellín. Instituto Popular de Capacitación (IPC), Fundación Forjando Futuros, Universidad de San Buenaventura Medellín, Comisión Nacional De Reparación y Reconciliación y Personería de Medellín.

Insuasty, A. y Vallejo, Y. (2012). ¿Crear ambiente para la paz? Análisis de coyuntura América Latina y Caribe. Revista Kavilando, 4(1), 18-19. https://dialnet.unirioja.es/descarga/articulo/4710515.pdf

La historia desconocida de los falsos positivos (2011). Semana. http:// www.semana.com/nacion/articulo/la-historia-desconocida-falsos-positi$\operatorname{vos} / 241215-3$

Las seis preguntas claves del caso contra los Nule (2011). El Tiempo. https://www.eltiempo.com/justicia/ARTICULO-WEB-NEW_NOTA_INTERIOR-9114027.html

La ONU raja a Colombia en Derechos Humanos (2014). Semana. http:// www.semana.com/nacion/articulo/la-onu-alerta-sobre-violacion-de-derechos-humanos-en-colombia/381675-3

Martín-Baró, I. (2000). Psicología social de la guerra: trauma y terapia. UCA. 
Maturana, H. (1997). La democracia es una obra de arte. Colombia. Cooperativa Editorial Magisterio.

Media Colombia con zonas de rehabilitación (2002). El Tiempo. https://www.eltiempo.com/archivo/documento/MAM-1349263

Ministerio de Salud, Ministerio de la Protección Social - MINSALUD (2013). Programa de atención psicosocial y salud integral a víctimas. http:// www.minsalud.gov.co/Documentos $\% 20 y \% 20$ Publicaciones/PAPSIVI $\% 20$ VERSION\%20PRELIMINAR\%2025\%20Febrero\%202013.doc

Morin, E. (1983). El método 2. La vida de la vida. Cátedra.

Morin, E. (1984). Ciencia con consciencia. Anthropos.

Morin, E. (1990). Introducción al pensamiento complejo. Gedisa Editorial.

Muere el Mono Jojoy, jefe militar de las FARC, en un bombardeo en Colombia (2010). El Mundo. https://www.elmundo.es/america/2010/09/23/ colombia/1285247247.htm

Naciones Unidas (2004). Informe de la Alta Comisionada de las Naciones Unidas para los Derechos Humanos sobre la situación de los derechos humanos en Colombia año 2004. http://www.hchr.org.co/documentoseinformes/informes/altocomisionado/Informe2003_esp.pdf

Naciones Unidas (2005). Informe de la Alta Comisionada de las Naciones Unidas para los Derechos Humanos sobre la situación de los derechos humanos en Colombia año 2005. http://www.hchr.org.co/documentoseinformes/informes/altocomisionado/Informe2005_esp.pdf

Naciones Unidas (2006). Informe de la Alta Comisionada de las Naciones Unidas para los Derechos Humanos sobre la situación de los derechos humanos en Colombia año 2006. http://www.hchr.org.co/documentoseinformes/informes/altocomisionado/Informe2006_esp.pdf

Naciones Unidas (2007). Informe de la Alta Comisionada de las Naciones Unidas para los Derechos Humanos sobre la situación de los derechos humanos en Colombia año 2007. http://www.hchr.org.co/documentoseinformes/informes/altocomisionado/2007/Informe $\% 20$ Alta $\% 20$ Comisionada $\% 20$ 2007\%20Espanol\%20ADVANCE\%20EDITED.pdf

Naciones Unidas (2008). Informe de la Alta Comisionada de las Naciones Unidas para los Derechos Humanos sobre la situación de los derechos humanos en Colombia año 2008. http://www.hchr.org.co/documentoseinformes/informes/altocomisionado/Informe2008_esp.pdf

Naciones Unidas (2009a). Indicadores de derechos humanos y derecho internacional humanitario para Colombia. http://www.acnur.org/t3/uploads/ media/COI_2775.pdf?view=1 
Naciones Unidas (2009b). Informe de la Alta Comisionada de las Naciones Unidas para los Derechos Humanos sobre la situación de los derechos humanos en Colombia año 2009. http://www.hchr.org.co/documentoseinformes/informes/altocomisionado/Informe2009_esp.pdf

Naciones Unidas (2010). Informe de la Alta Comisionada de las Naciones Unidas para los Derechos Humanos sobre la situación de los derechos humanos en Colombia año 2010. http://www.hchr.org.co/documentoseinformes/informes/altocomisionado/Informe2010_esp.pdf

Naciones Unidas (2011). Informe de la Alta Comisionada de las Naciones Unidas para los Derechos Humanos sobre la situación de los derechos humanos en Colombia. http://www.hchr.org.co/documentoseinformes/ informes/altocomisionado/informe2011.pdf

Naciones Unidas (2012). Informe de la Alta Comisionada de las Naciones Unidas para los Derechos Humanos sobre la situación de los derechos humanos en Colombia. http://www.hchr.org.co/documentoseinformes/ informes/altocomisionado/informe2012.pdf

Naciones Unidas (2013a). Informe anual de la Alta Comisionada de las Naciones Unidas para los Derechos Humanos. http://www.hchr.org.co/ documentoseinformes/informes/altocomisionado/informe2013.pdf

Naciones Unidas (2013b). Informe de la Alta Comisionada de las Naciones Unidas para los Derechos Humanos sobre la situación de los derechos humanos en Colombia año. http://www.hchr.org.co/documentoseinformes/ informes/altocomisionado/informe2013.pdf

Novoa, C. (2005). Tratado de Libre Comercio (TLC) y derechos humanos. https://revistas.javeriana.edu.co/index.php/internationallaw/article/ view/14050

Oficina Internacional de los Derechos Humanos Acción Colombia (OIDHACO) (2014). La situación de los derechos humanos en Colombia: declaración escrita de Amnistía Internacional ante el CDH. http://www.oidhaco.org/?lang=es

Organización de las Naciones Unidas (ONU) (2010). Programa de las Naciones Unidas para los Asentamientos Humanos. State of the World's Cities 2010/2011: Brinding the urban divide, ONU-Hábitat, 2010. https://www. un.org/ruleoflaw/es/un-and-the-rule-of-law/united-nations-human-settlements-programme/

Organización Mundial Contra la Tortura (OMCT) (2003). Colombia: llamado especial - situación de los defensores de derechos humanos - mayo de 2003. http://www.omct.org/es/human-rights-defenders/urgent-interventions/colombia/2003/06/d16328/ 
ONU alerta por graves violaciones de derechos humanos en Colombia (2010). Noticias Caracol. https://caracol.com.co/radio/2010/08/01/internacional/1280644260_334887.html

Pécaut, D. (1987). Orden y violencia. Siglo XXI.

Pécaut, D. (2001). Guerra contra la sociedad. Editorial Planeta.

Pécaut, D. (2003). Violencia y política en Colombia. Elementos de reflexión. Hombre Nuevo Editores.

Pizarro, E. (2009). Ley de Justicia y Paz. Colección Cara y Sello, Grupo Editorial Norma.

Plan Nacional de Educación en Derechos Humanos (PLANEDH) (2006). http://www2.ohchr.org/english/issues/education/training/docs/ColombiaPLANEDH.pdf

Plan patriota (2006). Semana. http://www.semana.com/on-line/articulo/plan-patriota/70525-3

Posada, M. C., Insuasty, A., Vega, G. y Balbín, J. W. (2009). Víctimas, violencia y despojo. Informe de la investigación acerca de víctimas del conflicto armado. Editorial Universidad de San Buenaventura Medellín

Programa Presidencial de Derechos Humanos y Derecho Internacional Humanitario (PPDH-DIH) (2013). Cifras violaciones a los derechos a la vida e integridad julio de 2012. http://www.derechoshumanos.gov.co/Observatorio/Documents/Cifras-Nacionales-a-Julio-2012.pdf

Quiñones, S. (2012). Blanqueo de tierras en Colombia. Diario Periodismo Humano. http://periodismohumano.com/en-conflicto/blanqueo-de-tierras-en-colombia-la-guerra-como-coartada-para-arrebatar-a-los-campesinos-10-millones-de-hectareas.html

República de Colombia (2005). Ley 975 de 2005. Fiscalía general de la nación - Relatoría unidad de justicia y paz. http://www.fiscalia.gov.co/jyp/ wp-content/uploads/2013/04/Ley-975-del-25-de-julio-de-2005-concordadacon-decretos-y-sentencias-de-constitucionalidad.pdf

República de Colombia (2010). Sentencia T-045 de 2010. Víctima de conflicto armado interno que ostenta la calidad de desplazado goza de una protección constitucional reforzada. http://www.corteconstitucional.gov.co/ relatoria/2010/t-045-10.ht

República de Colombia (2013a). Auto 099 de 2013. Referencia: sentencia T-025 de 2004 y autos 178 de 2005, 008 de 2009, 314 de 2009, 383 y 385 de 2010, y 219 de 2011. "II. Diagnóstico de las falencias en el componente de ayuda humanitaria y respuesta del gobierno nacional". http://www.corteconstitucional.gov.co/relatoria/autos/2013/a099-13.HTM 
República de Colombia (2013b). Comisión Interamericana de Derechos Humanos saca a Colombia del Capítulo IV en su Informe Anual 2012. http:// wsp.presidencia.gov.co/cepri/noticias/2013/abril/Paginas/20130418_04.aspx

Rojas, M. (2007). Plan Colombia II: ¿más de lo mismo? Colombia Internacional, (65), 14-37.

Servicio Internacional Cristiano de Solidaridad con los pueblos de América Latina (SICSAL) (2007). Colombia informe anual 2007. http://www. sicsal.net/articulos/node/586

Tickner, A. (2007). Intervención por invitación. Claves de la política exterior colombiana y de sus debilidades principales. Revista Colombia Internacional, (65), 90-111. http://colombiainternacional.uniandes.edu.co/ view.php/93/view.php

Villa, J. D. (2007). "Si no fuera por Dios, nosotros ya nos hubiéramos muerto" Víctimas, reconciliación y religión. Theologica Xaveriana, 57(164), 565-590.

Villa, J. D. (2012). La acción y el enfoque psicosocial de la intervención en contextos sociales: ¿podemos pasar de la moda a la precisión teórica, epistemológica y metodológica? Revista El Ágora, 12(2), 349-365.

Wiesner, E. (2004). El origen político del déficit fiscal en Colombia: el contexto institucional 20 años después. Bogotá: Documento CEDE, 20. https://economia.uniandes.edu.co/components/com_booklibrary/ebooks/ d2004-20.pdf 